\title{
A probabilistic approach for risk-benefit assessment of food substitutions: A case study on substituting meat by fish
}

Thomsen, Sofie Theresa; de Boer, Waldo; Pires, Sara Monteiro; Devleesschauwer, Brecht; Fagt, Sisse; Andersen, Rikke; Poulsen, Morten; van der Voet, Hilko

\section{Published in:}

Food and Chemical Toxicology

Link to article, DOI:

10.1016/j.fct.2019.02.018

Publication date:

2019

Document Version

Peer reviewed version

Link back to DTU Orbit

Citation (APA):

Thomsen, S. T., de Boer, W., Pires, S. M., Devleesschauwer, B., Fagt, S., Andersen, R., Poulsen, M., \& van der Voet, H. (2019). A probabilistic approach for risk-benefit assessment of food substitutions: A case study on substituting meat by fish. Food and Chemical Toxicology, 126, 79-96. https://doi.org/10.1016/j.fct.2019.02.018

\section{General rights}

Copyright and moral rights for the publications made accessible in the public portal are retained by the authors and/or other copyright owners and it is a condition of accessing publications that users recognise and abide by the legal requirements associated with these rights.

- Users may download and print one copy of any publication from the public portal for the purpose of private study or research.

- You may not further distribute the material or use it for any profit-making activity or commercial gain

- You may freely distribute the URL identifying the publication in the public portal 


\section{Accepted Manuscript}

A probabilistic approach for risk-benefit assessment of food substitutions: A case study on substituting meat by fish

Sofie Theresa Thomsen, Waldo de Boer, Sara M. Pires, Brecht Devleesschauwer, Sisse Fagt, Rikke Andersen, Morten Poulsen, Hilko van der Voet

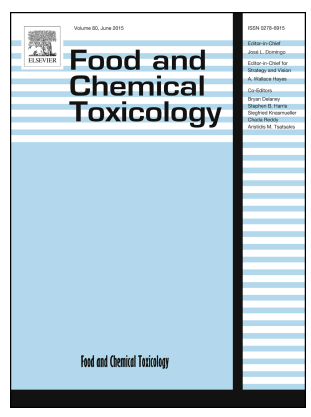

PII: S0278-6915(19)30069-9

DOI: https://doi.org/10.1016/j.fct.2019.02.018

Reference: $\quad$ FCT 10345

To appear in: Food and Chemical Toxicology

Received Date: 8 December 2018

Revised Date: 1 February 2019

Accepted Date: 6 February 2019

Please cite this article as: Thomsen, S.T., de Boer, W., Pires, S.M., Devleesschauwer, B., Fagt, S., Andersen, R., Poulsen, M., van der Voet, H., A probabilistic approach for risk-benefit assessment of food substitutions: A case study on substituting meat by fish, Food and Chemical Toxicology (2019), doi: https://doi.org/10.1016/j.fct.2019.02.018.

This is a PDF file of an unedited manuscript that has been accepted for publication. As a service to our customers we are providing this early version of the manuscript. The manuscript will undergo copyediting, typesetting, and review of the resulting proof before it is published in its final form. Please note that during the production process errors may be discovered which could affect the content, and all legal disclaimers that apply to the journal pertain. 


\section{A probabilistic approach for risk-benefit assessment of food}

\section{substitutions: a case study on substituting meat by fish ${ }^{1}$}

Authors: Sofie Theresa Thomsen ${ }^{1}$, Waldo de Boer ${ }^{2}$, Sara M. Pires ${ }^{1}$, Brecht Devleesschauwer ${ }^{3,4}$,

Sisse Fagt ${ }^{5}$, Rikke Andersen ${ }^{1}$, Morten Poulsen $^{1}$, Hilko van der Voet ${ }^{2}$

${ }^{1}$ Division of Diet, Disease Prevention and Toxicology, National Food Institute, Technical University of Denmark, Kemitorvet, Building 202, 2800 Kgs. Lyngby, Denmark.

${ }^{2}$ Biometris, Wageningen University \& Research (WUR), Droevendaalsesteeg 1, 6708 PB Wageningen, The Netherlands.

${ }^{3}$ Department of Epidemiology and Public Health, Sciensano, Juliette Wytsmanstreet 14, 1050 Brussels, Belgium.

${ }^{4}$ Department of Veterinary Public Health and Food Safety, Faculty of Veterinary Medicine, Ghent University, Salisburylaan 133, 9820 Merelbeke, Belgium.

${ }^{5}$ Division of Risk Assessment and Nutrition, National Food Institute, Technical University of Denmark, Kemitorvet, Building 202, 2800 Kgs. Lyngby, Denmark.

\footnotetext{
${ }^{1}$ Abbreviations: AI: Adequate Intake; AR: Average Requirement; BLUP: Best Linear Unbiased Predictor; Bw: Body weight; CHD: Coronary Heart Disease; CRC: Colorectal Cancer; DALY: Disability-Adjusted Life Year; DANSDA: Danish National Survey of Diet and Physical Activity; DHA: Docosahexaenoic Acid; dl-PCB: Dioxin-Like Polychlorinated Biphenyls; DW: disability weight; EPA: Eicosapentaenoic Acid; FBDG: Food-Based Dietary Guidelines; GIES: General Intake Estimation System; IQ: Intelligence Quotient; LE: Life Expectancy; LNN: Logisticnormal normal; MeHg: Methyl Mercury; NCSC: Non-Cardia Stomach Cancer; OIM: Observed Individual Mean; P2.5: 2.5 ${ }^{\text {th }}$ Percentile, P10: $10^{\text {th }}$ Percentile; P50: 50 ${ }^{\text {th }}$ Percentile; P90: $90^{\text {th }}$ Percentile; P97.5: 97.5 ${ }^{\text {th }}$ Percentile; RBA: RiskBenefit Assessment; SD: Standard Deviation; TEQ: Toxic Equivalents; TWI: Tolerable Weekly Intake; UID: usual intake difference; YLD: Years Lived with Disability; YLL: Years of Life Lost.
} 
* Corresponding author: Sofie Theresa Thomsen, Technical University of Denmark, National Food Institute, Kemitorvet, building 201, room 115, 2800 Kgs. Lyngby, Denmark.

Phone: +45 35887562; e-mail: sthth@food.dtu.dk 


\begin{abstract}
Accounting for substitution of foods is inevitable when evaluating health impact of dietary changes. But substitution behavior and the associated health impact may vary between individuals. We therefore propose the use of probabilistic methods to model substitution and assess health impact distributions in risk-benefit assessment (RBA) of foods.
\end{abstract}

We investigated the health impact of substituting red and processed meat with fish in the Danish adult population and the variability in health impact. We applied probabilistic approaches in modeling the substitution to reflect variability between individual substitution behaviors. Furthermore, when multiple intake scenarios are compared, we propose a method for adjusting intake differences for individual day-to-day variability.

We estimated that 134 (95\% UI: 102; 169) Disability-Adjusted Life Years/100,000 were averted per year by the substitution. The health impact varied considerably by age and sex, with the largest health benefit of the substitution observed for young women in the child-bearing age and for the older generation, mainly men.

This study provides further insight in how the health impact of substituting meat by fish varies between individuals and suggests a framework to be applied in RBAs of other food substitutions. Our results are relevant for policy makers in defining targeted public health strategies. 


\section{Introduction}

Suboptimal diet has been ranked the leading behavioral risk factor for total global deaths and the second-leading risk factor for global disease burden by the Global Burden of Disease (GBD) 2017 Study (GBD 2017 Risk Factor Collaborators 2018). Based on these results, the need for action on promoting healthier diets both on a national and international level was stressed. Risk-benefit assessment (RBA) of foods is a multidisciplinary tool that offers support to policy makers by providing evidence on the net health impact of potential dietary interventions and thus guidance for health promotion. RBA includes other areas in addition to nutrition, such as toxicology and microbiology, allowing for an integrated assessment of the consequences of food consumption on human health (EFSA NDA Panel 2010b; Tijhuis et al. 2012; Verhagen et al. 2012).

The majority of RBAs published so far has focused on increasing or decreasing the consumption of single foods without including substitution of foods. However, individual foods are part of a whole diet, and thus the scenarios of RBAs investigating changes in consumption of foods do not reflect interventions in a real-life setting. Few RBAs have included substitution of food components (Hendriksen et al. 2011; Husøy et al. 2008; Verhagen et al. 2012) and of foods (Hollander et al. 2018; Roodenburg et al. 2013; Temme et al. 2015, 2013; Tetens et al. 2013b; Thomsen et al. 2018; van der Voet et al. 2007). Whereas substitutions of food components, such as food fortification or replacement of one food component with another, are easier to model, food substitutions may be more complex and variable between individuals, making it difficult to predict how people will substitute. The substitution of red meat with fish has been investigated in a few previous RBAs (Hollander et al. 2018; Tetens et al. 2013b; Thomsen et al. 2018; van der Voet et al. 2007). These RBAs were based on the assumption that all individuals behave in the same way, either by assuming a fixed percentage of red meat being substituted with fish gram by gram (van der Voet et 
al. 2007) or by aiming for recommended consumption levels and conducting the substitution using fixed substitution factors (Thomsen et al. 2018) or gram by gram substitution (Hollander et al. 2018; Tetens et al. 2013b). In neither of these RBAs individual variability in fish species or meat product preferences was taken into account, except the variability originating from the baseline scenarios. However, substitution behavior may differ between individuals (Nauta et al. 2018). Upon implementation of dietary policies, some individuals will likely not reach the recommended consumption level while others will consume more (Fransen et al. 2010; Nordic Council of Ministers 2006). This variability in behavior may be reflected in the net health impact of the intervention both at the individual and population level.

In this RBA, we took a probabilistic approach in modeling the substitution of red (processed and unprocessed) meat with fish in the Danish diet in order to model the variability in the substitution behavior and in the health impact of the substitution between individuals. We proposed a probabilistic method for estimating usual intake differences between two scenarios of behavior, i.e. we estimated the between-individual variability in difference adjusting for within-individual variability, based on established models for usual intakes. We estimated the health impact of changing from the current consumption of fish, red meat, and processed meat in the Danish population (reference scenario) to an alternative scenario in which part of the red and processed meat consumed was substituted by fish. The health impact of the substitution was quantified in terms of Disability-Adjusted Life Years (DALYs) on an individual level as well as on a population level in order to gain insight in the variability in the health impact of the substitution, including which subgroups would achieve the highest health gain and at the potential expense of other subgroups. 


\section{Methods}

This study builds on a previous RBA of substituting red and processed meat with fish in the Danish adult diet (Thomsen et al. 2018), additionally accounting for variability in substitution behavior and the associated health impact. 'Red meat' was defined as beef, pork, lamb, and goat (WCRF/AICR 2007). 'Processed meat' covered in this study red meat preserved by smoking, curing, salting, or addition of chemical preservatives. Furthermore, we defined 'fish' as both vertebrate and invertebrate seafood. We considered the following health effects: fetal neurodevelopment associated with maternal fish consumption and $\mathrm{MeHg}$ exposure; coronary heart disease (CHD) mortality risk associated with intake of the fatty acids docosahexaenoic acid (DHA) and eicosapentaenoic acid (EPA); hypothyroidism and male infertility risk associated with exposure to dioxin and dioxin-like (dl-) polychlorinated biphenyls (PCBs); colorectal cancer (CRC) risk associated with red and processed meat consumption; and non-cardia stomach cancer (NCSC) risk associated with processed meat consumption.

\subsection{Data}

Data on individual dietary intake on seven consecutive days were provided by the Danish National Survey of Diet and Physical Activity (DANSDA) (Pedersen et al. 2015) and form the basis of the intake modeling. Data were available for 3,946 individuals aged 4-75 years. We included only those individuals that reported for all seven consecutive days of the survey and had information on measured height and bodyweight (bw) summing to a total of 2,811 individuals and 19,677 individual days. Consumption data were given on an ingredient level and as edible uncooked weights except for industrially processed foods (e.g. canned/smoked fish and processed meats). Before the substitution, consumption amounts of red meat, poultry and fish consumed in hot meals were converted into cooked amounts assuming water and fat loss dependent on animal origin and fat contents (Karin Hess Ygil, personal communication). 
Nutrient and chemical concentration data for food on the Danish market were obtained from Danish food monitoring (DTU 2017; Larsen et al. 2002; Petersen et al. 2015b, 2015a) (Supplemental Material 1-3). When concentration data were available from multiple sources we took the mean of the concentrations and weighted by the number of samples when this information was available. No information on the uncertainty around these concentration values was available. Data on fat and water loss, concentration of iron and vitamin D, retention of iron, and energy in the foods included in the substitution model are presented in Supplemental Material 1. Fish was assumed the only source of MeHg, and DHA and EPA, whereas the exposure to dioxin and dl-PCBs was also estimated from other sources including meat. Supplemental Material 2 shows the mean concentrations of MeHg, dioxin + dl-PCBs, DHA and EPA in fish. Concentrations of dioxin + dlPCBs in other foods contributing to exposure are shown in Supplemental Material 3. Concentrations of dioxin + dl-PCBs are given in Toxic Equivalents (TEQ) (WHO 2000). We did not account for any contributions to nutrient intakes from supplements.

\subsection{Identification of under- and over-reporters}

We estimated individual basal metabolic rates based on information on sex, age, and measured height and bw using the Oxford equations by Henry (Henry 2005) as indicated in Supplemental Material 4. We identified under- and over-reporters in the dietary survey by the Goldberg cut-off method as described by Black (Black 2000) using a lower and upper cut-off value for the ratio between the estimated energy intake and basal metabolic rate of 1.05 and 2.28 , respectively.

We performed the substitution modeling both with and without under- and over-reporters included to investigate the impact. 


\subsection{Substitution model}

Our substitution model aimed at reaching the currently recommended intake of fish of $350 \mathrm{~g} /$ week for at least $70 \%$ of the study population and correspondingly decreasing the consumption of red and processed meat (Nordic Council of Ministers 2006; Tetens et al. 2013a).

The substitution was performed on an individual-day level, and both intake frequencies and amounts during all days of DANSDA, $j=\{1, \ldots, 7\}$, were considered in order to reach the recommendations for each individual $i$. The overall framework of the substitution model is shown in Figure 1. We defined the target weekly fish consumption as a stochastic variable described by a lognormal distribution (Koch 1966). For the lognormal distribution we have:

$$
\begin{gathered}
\text { median }=\exp (\mu) \\
\text { standard deviation }=\sqrt{\left(\exp \left(\sigma^{2}\right)-1\right) \exp \left(2 \mu+\sigma^{2}\right)}
\end{gathered}
$$

where $\mu$ and $\sigma$ are the mean and standard deviation of the normally distributed log-transformed consumption amounts. For a range of $\sigma$ values, we investigated a range of values of $\mu$ to identify what values would lead to the target of $70 \%$ of the population consuming $>350 \mathrm{~g} /$ week after substitution. We found that defining the weekly fish consumption as a lognormal distribution with $\mu=\ln (405)$ and $\sigma=0.75$ (corresponding to standard deviation $[S D]=466$ conforms to this target after substitution while at the same time it does not lead to unreasonably high or low fish consumption amounts in the tails of the distribution. We considered a weekly consumption above $140 \mathrm{~g}$ for the P2.5 and below $1750 \mathrm{~g}$ (i.e. on average $250 \mathrm{~g} /$ day) for the P97.5 as a reasonable range for the weekly target fish consumption. 
For each individual $i$, a personal weekly fish consumption target, $X_{f i \text { ish,i,target }}$, was sampled from this distribution. We calculated the current weekly fish consumption by individual $i$ as $X_{f i s h, i, 0}=\sum_{j=1}^{n_{\text {days }}} \sum_{t=1}^{n_{f i s h}} X_{t i j 0}$, where $X_{t i j 0}$ is the current fish consumption of fish type $t$ for individual $i$ on day $j$. When $X_{f i s h, i, 0}<X_{f i s h, i, \text { target }}$, individual $i$ was subject to the substitution. Otherwise, the current fish consumption of individual $i$ was left unchanged.

The substitution model ensures that the personal target fish consumption level is achieved by increasing the consumption of fish to a minimum of 3 days per week, based on data for individuals that already achieved this frequency. Thus, for each individual not reaching $X_{f i s h_{,}, i_{n}, t a r g e t}$ by its current consumption, a new target fish consumption frequency (proportion days in a week, $P_{f i s h, i}^{\prime}$ ) is sampled from the observed distribution of consumption frequencies for individuals that consumed fish $\geq 3$ days/week. As shown in Figure 1, increasing the fish consumption frequency is an iterative process by one day at a time, and it is only further increased up to a maximum of $P_{\text {fish,i }}^{\prime}$ if the target weekly fish consumption amount is not already reached at lower frequencies.

For each new fish consumption day, new fish consumption amounts were sampled. Frequency distributions of intake of the individual types of fish consumed in the Danish population based on the original consumption data were used for sampling fish types to be substituted on new consumption days. Next, fish-type specific consumption amounts, $X_{t i j}^{\prime}$, were sampled for individual $i$ on day $j$ from the empirical distribution of non-zero amounts of fish type $t$ consumed in the original consumption data.

The model was defined such that individuals only consume one type of fish on a new fish consumption day. If $X_{f i s h, i} i_{n}$ target was not met by increasing the fish consumption frequency up to a 
maximum frequency of $P_{f i s h, i}^{\prime}$, all consumption amounts for individual $i$ were proportionally increased to $X_{f i s h, i, t a r g e t}$ by:

$$
X_{f i s h, i, j, a l t}=\frac{X_{f i s h, i, j, 1} \cdot X_{f i s h, i, t a r g e t}}{X_{\text {total fish }, i_{,}, 1}}
$$

where $X_{f i s h_{i}, i_{j}, a l t}$ is the fish consumption amount for individual $i$ on day $j$ in the alternative scenario and $X_{f i s h, i, j, 1}$ is the new fish consumption for individual $i$ on day $j . X_{f i s h, i, j, 1}$ may be either a sampled new fish consumption amount for individual $i$ on day $j\left(X_{t i j}^{\prime}\right)$ or may be the current fish consumption for individual $i$ on day $j\left(X_{f i s h, i, j, 0}\right)$ before substitution. If the recommended fish consumption level was already met, then:

$$
X_{f i s h, i, j, a l t}=X_{f i s h, i_{i}, 1}
$$

Finally, the new total weekly fish consumption amounts in the alternative scenario are equal to:

$$
X_{f i s h, i, a l t}=\sum_{j=1}^{n_{\text {days }}} \sum_{t=1}^{n_{f i s h}} X_{t, i, j, a l t}
$$

We assumed that an increase in the consumption of fish typically consumed on bread (in cold meals) would cause a decrease in red meat consumed on bread (in cold meals). Likewise, we assumed that an increase in fish typically consumed in hot meals would substitute red meat typically consumed in hot meals. Thus, the increase in fish consumption from $X_{f i s h, i, 0}$ to $X_{f i s h, i, a l t}$ would cause a decrease in the consumption of red meat (consumed in cold and/or hot meals) for individual $i$ on the individual days $j$. If the current individual consumption of red meat for either cold or hot meals was not sufficient to compensate for the increase in fish consumption, then poultry was substituted. If the individual consumption of poultry before substitution was not 
sufficient to compensate for the increased fish consumption either, the remaining amount of uncompensated increased fish consumption was not substituting for any other foods, but simply added to the individual daily consumption. Figure 1 shows the substituted foods and the foods that were substituted and the order of substitution. 


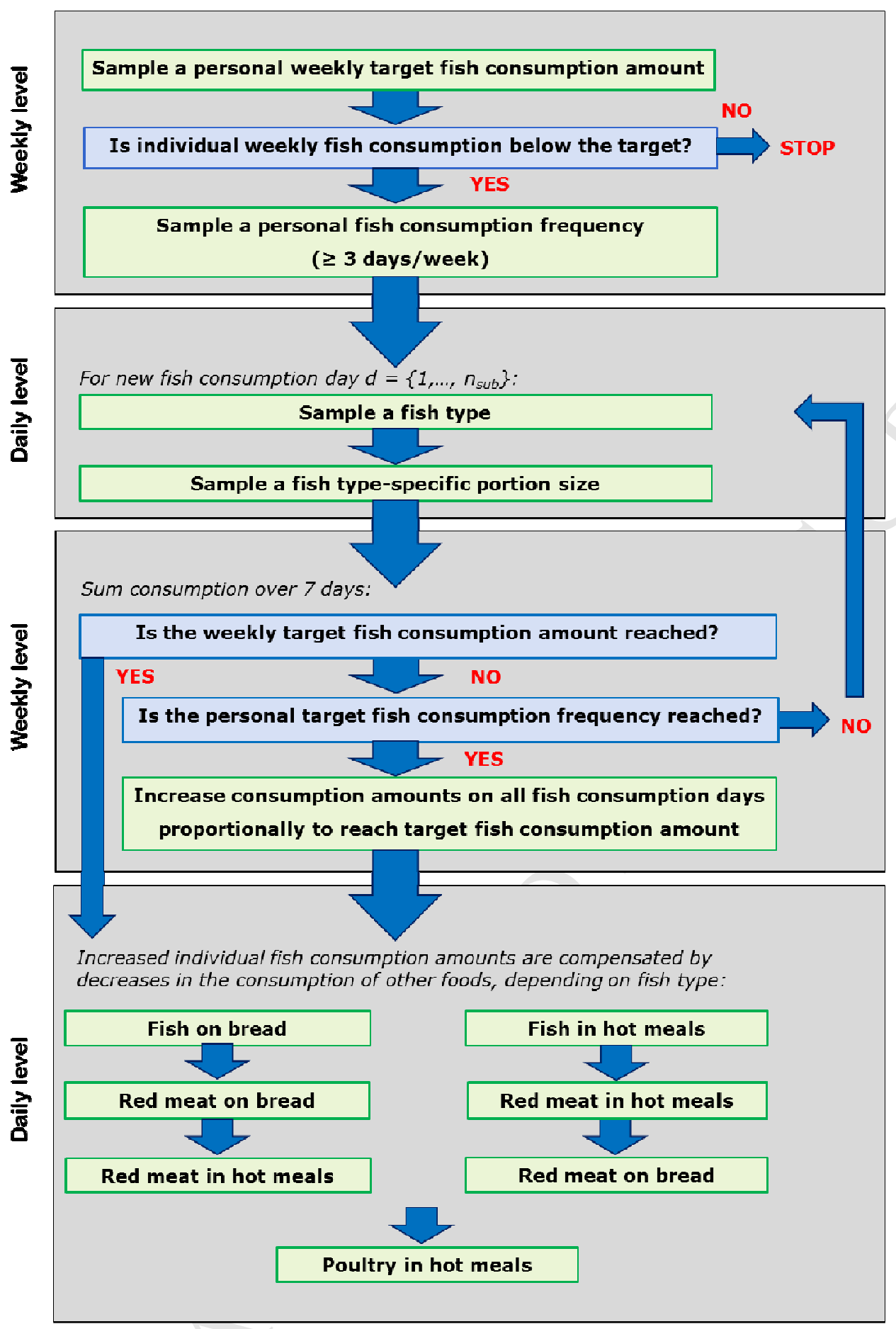

Figure 1 Overall framework of the substitution model. Flow chart showing the individual steps of the substitution model. Blue boxes indicate questions asked during the model and green boxes commands on actions that must be made. Each grey box indicates whether the model refers to daily or weekly consumption.

Abbreviations: $\mathrm{n}_{\text {sub }}$ : total number of new fish consumption days. 
The increase in fish consumption was translated into a decrease in consumption of red meat (in cold and/or hot meals) and poultry using substitution factors (Table 1). Portion sizes may vary between foods within each food group and between individuals, thus we defined the substitution factors as stochastic variables based on the relative proportions between Danish estimates of portion sizes of the substituted and substituting foods groups. We described the variability in the substitution factor as a PERT distribution and defined minimum, mode, and maximum values for each possible substitution between food groups based on expert elicitation (Karin Hess Ygil, personal correspondence). The decrease in the substituted food was calculated by multiplying the substituting food with the substitution factor. The classification into fish and red meat consumed in cold meals (on bread) and hot meals are given in Supplemental Material 6 and Supplemental Material 7, respectively. In the same table we group red meat into unprocessed red meat and processed red meat, which are distinguished due to differences in the health effects associated with their consumption.

We performed the substitution for each individual included from the survey $(n=2,811)$ using $\mathrm{R}$ version 3.5.1 (R Core Team 2018). The algorithm used for the substitution is presented in Supplemental Material 8.

\begin{tabular}{|l|l|}
\hline \multicolumn{1}{|c|}{ Food substitution } & \multicolumn{1}{c|}{ Substitution factor } \\
\hline Fish on bread $\rightarrow$ red meat on bread & PERT $(\min =0.1, \operatorname{mode}=0.4, \max =1)$ \\
\hline Fish in hot meal $\rightarrow$ red meat in hot meals & PERT $(\min =0.7$, mode $=1, \max =7.5)$ \\
\hline Red meat on bread $\rightarrow$ red meat in hot meals & PERT $(\min =2.8$, mode $=5.7, \max =15)$ \\
\hline Red meat in hot meals $\rightarrow$ poultry in hot meals & PERT $(\min =0.6, \operatorname{mode}=1, \max =1.6)$ \\
\hline
\end{tabular}

Table 1 Stochastic substitution factors used to convert substitution between food groups. 


\subsection{Usual intake model}

All health effects considered in this study are of a chronic nature, being dependent on average longterm intake rather than short-term intake. We refer to the average long-term intake as the usual intake. Intake can refer either to the consumption of foods (e.g. fish) or to the exposure to food components (e.g. nutrients and contaminants). We modeled the usual intake of each food and food component present in foods that were changed as a consequence of the substitution model, and that were directly associated with a health effect in humans, i.e. fish, DHA + EPA, MeHg, dioxin + dlPCBs, processed meat, and red meat. We modeled the usual intake of these foods and food components in the reference and the alternative scenario. In addition, the usual intake of iron and vitamin $\mathrm{D}$ before and after substitution and the changes in energy intake were modeled. Furthermore, we estimated the risk of inadequacy of vitamin D and iron before and after substitution.

Exposure to food components (nutrients, contaminants) on individual days were estimated by multiplying the intake of individual foods for individual $i$ on day $j$ (g/day) with concentration data (unit per g food) for the specific foods and food components. Similarly, changes in intake of iron, vitamin $\mathrm{D}$, and energy were estimated based on the changes in intake of individual foods on individual-days. Exposure to contaminants was expressed per kg bw. Data on individual-day total intakes of iron and vitamin $\mathrm{D}$ from the whole diet in the reference scenario were obtained from the General Intake Estimation System (GIES) software (version 1.000d; developed at the National Food Institute, Technical University of Denmark, Copenhagen, Demark), and the Danish Food Composition Databank (DTU 2017). Total intakes of iron and vitamin D were combined with 
changes in intake of the micronutrients due to the substitution to estimate total intakes in the alternative scenario.

\subsubsection{The Observed Individual Means model}

The Observed Individual Means (OIM) model is a simple naive approach to estimate long-term intake and is the default used in basic probabilistic modeling of exposure to pesticides by the European Food Safety Authority (EFSA 2012). It takes for each individual the sum of the daily food consumption amounts divided by the total number of individual person-days:

$$
Z_{f i}=\frac{\sum_{j} X_{f i j}}{n_{\text {days }}}, \quad j=\left\{1, \ldots, n_{\text {days }}\right\}
$$

where $X_{f i j}$ is the food consumption amount of food or food component $f$ of individual $i$ consumed on day $j$. Simply taking the mean consumption over these seven days will not average out all of the within-individual variability. The mean of the OIM distribution is equal to the mean of the true usual intake distribution but the distribution is wider compared to the true usual intake distribution, causing an overestimation of the tails (Goedhart et al. 2012).

\subsubsection{The Logistic-Normal Normal model}

Where the OIM model does not adjust for within-individual variability, the so-called logisticnormal normal (LNN) model does. The true usual intake distribution is estimated by fitting a twopart model to the observed daily food consumption amounts. The first part models the variability in food consumption frequencies with a logistic-normal distribution, and the second part the variability in food consumption amounts with a normal distribution on an appropriate scale. After fitting both distributions, they are numerically integrated (Goedhart et al. 2012; van der Voet et al. 2015).

The so-called model-assisted approach allows for modeling individual usual intakes while keeping information on individual characteristics and food intake as opposed to the model-based approach, 
where the usual intake distribution is simulated using a fully parametric approach (Goedhart et al. 2012).

It is reasonable to assume that the observed individual intake frequency of food or food component $f, P_{f i}$, is a representable approximation of the true usual intake frequency in the first part of the LNN model:

$$
P_{f i}=\frac{n_{\text {days }, f, i}}{n_{\text {days }}}
$$

where $n_{\text {days }, f, i}$ is the number of non-zero intake days of food or food component $f$ for individual $i$ and $n_{\text {days }}$ is the total number of days of the dietary survey.

In the second part of the LNN model, the variability of the individual daily intake amounts is estimated. First, positive daily intake amounts are brought to approximate normality by a transformation using the Box-Cox family of power transforms. The natural logarithm is a special case of this family.

Secondly, the transformed positive daily intake amounts are modeled with a variance components model and the mean, between-individual and within-individual effects are estimated with:

$$
\operatorname{trans} f\left(X_{f i j}\right)=\mu_{f i}+\varepsilon_{f i}+\delta_{f i j}
$$

where $X_{f i j}$ is the intake amount of food or food component $f$ for individual $i$ on day $j, \mu_{f i}$ is the mean transformed usual intake amount of food or food component $f$ for individual $i$, and $\varepsilon_{f i}$ and $\delta_{f i j}$ are the between-individual and within-individual effects, respectively, and are assumed to be normally distributed, $N\left(0, \sigma_{f b}^{2}\right)$ and $N\left(0, \sigma_{f w}^{2}\right)$ with $\sigma_{f b}^{2}$ and $\sigma_{f w}^{2}$, the between-individual and 
within-individual variances, respectively, for the given food or food component $f$ (de Boer et al. 2009; Slob 2006; van der Voet et al. 2007).

The model-assisted usual intake amount on the transformed scale or the Best Linear Unbiased Predictor (BLUP) for $\left(\mu_{f i}+\varepsilon_{f i}\right)$ is given by:

$$
B L U P_{f i}=\mu_{f i}+\left(Z_{f i}-\mu_{f i}\right) * \sqrt{w_{f i}}
$$

where $Z_{f i}$ is the mean of the transformed intake amounts of food or food component $f$ for individual $i$ on non-zero consumption days. $B L U P_{f i}$ represents the best predictor for the usual intake amount of an individual and is estimated by shrinking the mean of the observed individual intake amounts towards the sample population mean where the amount of shrinkage is determined by:

$$
w_{f i}=\frac{\sigma_{b}^{2}}{\sigma_{b}^{2}+\sigma_{w}^{2} / n_{\text {days }, j, i}}
$$

and $n_{\text {days }, f, i}$ is the number of non-zero consumption days of food or food component $f$ for individual $i$.

The predicted mean usual intake amount over the non-zero consumption days is then backtransformed to the original scale. For the logarithmic transformation, the back-transformation and simultaneous bias-correction is (de Boer et al. 2009):

$$
Y_{f i}=\exp \left(B L U P_{f i}+\frac{\sigma_{w}^{2}}{2}\right)
$$

and for a power transform, a Taylor approximation for bias-correction is applied (Sakia 1990):

$$
Y_{f i}=\left(1+\lambda \cdot B L U P_{f i}\right)^{\frac{1}{\lambda}} \cdot\left(1+(1-\lambda) \cdot \frac{\sigma_{w}^{2}}{2} \cdot\left(1+\lambda \cdot B L U P_{f i}\right)^{-2}\right)
$$


In the integration step, the usual intake is calculated for each individual $i$ by multiplying the mean usual consumption amount over positive consumption days with the observed (empirical) individual consumption frequency:

$$
Z_{f i}=P_{f i} \cdot Y_{f i}
$$

\subsubsection{Four-part usual intake difference model}

Usual intake distributions are shrunken (more narrow) compared to the individual-day level intake distributions. The amount of shrinkage is estimated in each model run, and for two scenarios the shrinkage factors can be different. Due to different shrinkage factors for the reference and substitution scenarios we can get the paradoxical result that estimated usual intakes for some individuals may be decreased for fish and increased for meat, although of course the substitution at the individual-day level was zero or in the opposite direction. To avoid this situation, we developed a new model, which directly models the usual intake differences between the two scenarios, and combines it with the usual intake model for the reference scenario to obtain the usual intake distribution in the alternative scenario.

The new model-assisted four-part usual intake difference (UID) model distinguishes between individual intake days on which:

1. There was no intake of food or food component $f$ before or after substitution (denoted $\{0: 0\}$ ). No modeling needed.

2. There was no intake of food or food component $f$ before substitution but there was an intake after (denoted $\{0: 1\})$. The variance component model was applied on the intake in the alternative scenario and used for modeling the positive intake difference. 
3. There was an intake of food or food component $f$ before substitution but not after (denoted $\{1: 0\})$. The variance component model was applied on the intake in the reference scenario and used for modeling the negative intake difference.

4. There was both an intake of food or food component $f$ before and after substitution (denoted $\{1: 1\})$. As the modeling was performed on the transformed scale, simply fitting the variance component model to the transformed intake difference was not considered logical. From the logarithm rules we have that:

$$
\log (a)-\log (b)=\log \left(\frac{a}{b}\right)
$$

Thus, for $\{1: 1\}$ substitution days we modeled the transformed ratio between the intake in the alternative scenario and the intake in the reference scenario. We furthermore modeled substitution days where there was an increased $(\{1: 1+\})$ and decreased $(\{1: 1-\})$ intake separately. No modeling was necessary for $\{1: 1\}$ substitution days where the intake was unchanged (zero difference). The adjusted individual intake differences on $\{1: 1+/-\}$ days were estimated by multiplying the predicted and back-transformed individual intake ratios with the individual usual intakes in the reference scenario and subtracting the usual intake in the reference scenario.

For each individual $i$ we calculated the observed probability of $\{1: 0\},\{0: 1\},\{1: 1\},\{1: 1+\},\{1: 1-\}$ and $\{0: 0\}$ indicated by $P_{f, i, h}$ where $h=\{\{1: 0\},\{0: 1\},\{1: 1\},\{1: 1+\},\{1: 1-\},\{0: 0\}\}$. These probabilities were combined with individual mean usual intake differences for $h, \Delta Y_{f i n}$, estimated by the variance component model, in order to estimate the usual intake difference of food or food component $f$ for individual $i, \Delta Z_{f i}$ :

$$
\Delta Z_{f i}=P_{f, i,\{0: 1\}} \cdot \Delta Y_{f, i,\{0: 1\}}+P_{f, i,\{1: 1+\}} \cdot \Delta Y_{f, i,\{1: 1+]}+P_{f, i, i 1: 1-]} \cdot \Delta Y_{f, i,\{1: 1-\}}+P_{f, i, i: 0]} \cdot \Delta Y_{f, i, i, 0\}}
$$


The modeled individual usual intake difference, $\Delta Z_{f i}$, was added to the individual usual intake in the reference scenario to estimate the usual intake in the alternative scenario.

For a few individuals, small negative usual intakes were estimated in the alternative scenario as a result of the modeling. We rounded these negative numbers to zero. Given the very low proportion of individuals with small negative intakes $(<1 \%)$ we did not consider this rounding as violating the final intake distribution.

We tested for normality and adequacy of the fitted variance component model by plotting the observed versus theoretical residuals using a normal quantile-quantile (q-q) plot (de Boer et al. 2009). If non-normal behavior was observed, we used the OIM to model the usual intake or usual intake difference.

Finally, weighting factors ascribed to each individual in the survey were applied to the usual intake data to correct for skewness in the sample population compared to the Danish population in regards to age, sex and education. The weighting factors were used to simulate a total of 100,000 Danish individuals.

\subsection{Comparison with health-based guidance values and dietary reference values}

To support the DALY estimates, we compared the chemical exposures to established health-based guidance values for each of the contaminants considered. We estimated the proportion of the population above the tolerable weekly intake (TWI) for MeHg $(1.3 \mu \mathrm{g} / \mathrm{kg}$ bw/week corresponding to $0.19 \mu \mathrm{g} / \mathrm{kg}$ bw/day) (EFSA CONTAM Panel 2012) and the TWI for dioxin + dl-PCBs (14 pg TEQ/kg bw/week corresponding to $2 \mathrm{pg}$ TEQ/kg bw/day) (Scientific Committee on Food 2001) and below the adequate intake (AI) of DHA + EPA (250 mg/day) (EFSA NDA Panel 2010a). 
Due to lack of good dose-response functions, characterizing health effects associated with iron intake combined with methodological difficulties in determining iron status, we did not estimate the DALYs associated with the changes in intake of iron. To be consistent, we did not quantify the risks and benefits associated with changes in intake of other micronutrients either. However, fish and meat are important sources of these micronutrients in the Danish diet (Pedersen et al. 2015), thus, we estimated the fraction of individuals with usual intakes below the average requirement (AR) for vitamin D (7.5 $\mu \mathrm{g} / \mathrm{day})$ and iron (7 $\mathrm{mg} /$ day for men, $10 \mathrm{mg} /$ day for women in the childbearing age, and $6 \mathrm{mg}$ /day for post-menopausal women) to estimate risk of inadequacy before and after substitution (Nordic Council of Ministers 2014).

Substituting between foods may cause changes in total energy intake. The health consequences associated with changes in energy intake depend on individual physical activity, genetics, and other factors, which we were not able to assess in the current study. Thus, we were not able to quantify the potential health impact associated with changes in energy intake either. However, the changes in individual energy intakes due to the substitution were still considered relevant and were thus quantified and evaluated.

\subsection{Disability-Adjusted Life Years}

The health impact of the change in consumption of the foods considered was quantified in terms of the difference in DALYs between the scenarios. The DALY is a population health gap measure of the healthy life years lost due to loss of quality of life and due to premature death (Devleesschauwer et al. 2015). DALYs are the sum of the years lived with disability (YLD) and the years of life lost due to premature mortality (YLL). YLD for a given disease or health outcome is calculated as:

$$
Y L D_{s, a}=A C_{s, a} \cdot D \cdot D W
$$


where $A C_{s, a}$ is the annual number of cases of the disease for sex $s$ and age $a, D$ is the duration and $D W$ is the disability weight of the disease. YLL is calculated as:

$$
Y L L_{s, a}=A D_{s, a} \cdot S E Y L L_{s, a}
$$

where $A D_{s, a}$ is the annual number of deaths due to the disease for sex $s$ and age $a$, and $S E Y L L_{s, a}$ are the standard expected years of life lost for sex $s$ and age $a$ (WHO 2017). The difference in DALYs between an alternative scenario and the reference scenario $(\triangle D A L Y)$ is a measure for the health impact of changing from one scenario to another, where a positive DALY difference implies a health loss and a negative DALY difference implies a health gain.

In this study we estimated the DALY difference for each simulated individual in order to be able to couple the loss of healthy life with individual food consumption and information on age and sex. In other words, it made us able to trace back exactly which subgroups would experience the largest health impact due to the substitution. Calculating DALYs per simulated individual will give information on the variability in the health gain or loss between individuals in our population. Individual DALY differences were converted to healthy life-days lost by dividing the individual DALY differences by 365.25 days in a year.

We applied a two-dimensional Monte Carlo simulation for the DALY calculations in order to separate uncertainty from variability. We used 100,000 iterations for simulating variability and 1,000 iterations for simulating uncertainty. Each iteration represented one individual, so for each iteration of the uncertainty dimension, a total DALY difference estimate was based on 100,000 individuals. We reported the median and the $2.5^{\text {th }}$ and $97.5^{\text {th }}$ uncertainty bounds of this distribution. A negative DALY difference implies a health gain by the shift to the alternative scenario (decrease 
in disease burden) whereas a positive DALY difference implies a health loss (increased disease burden).

We applied the same overall disease models as in Thomsen et al., adapted to allow for conducting the calculations for each simulated individual in this study (Thomsen et al., 2018). The methodology for the health outcome specific individual DALY calculations is described in detail in Supplemental Material 10.

\subsection{Statistical analysis of DALY differences}

We calculated two-tailed pseudo p-values for the DALY difference between the reference and alternative scenario to test if the difference was significantly different from zero (Lesaffre and Lawson 2012). Pseudo p-values were calculated for the DALY difference for each health outcome:

$$
P \text {-value }=2 \cdot \min \left(\operatorname{Pr}\left(\triangle D A L Y_{\text {d,alt }}>0\right), \operatorname{Pr}\left(\triangle D A L Y_{\text {d,alt }}<0\right)\right)
$$

Where probabilities (Pr) were estimated as the proportion of the DALY difference simulations above or below zero, respectively. We applied a 5\% significance level.

We performed a variable importance analysis (sensitivity analysis) to investigate which input parameters contributed more to the overall uncertainty of the DALY differences for each health outcome. Specifically, we calculated partial correlation coefficients between the standardized Monte Carlo simulations for the uncertain input variables and the Monte Carlo simulations for the DALY differences. Each partial correlation coefficient represents, on a scale from -1 to 1 , the correlation between one input variable and the DALY difference, adjusted for the effect of the other input variables. 
All statistical analyses were performed using R version 3.5.1 (R Core Team 2018).

\section{Results}

\subsection{Under- and over-reporters}

Of the 2,811 participants aged 15-75 years with information on height and bw in the dietary survey, $404(15 \%)$ were identified as under-reporters and $155(4 \%)$ as over-reporters. We ran the substitution model on both populations (with and without under- and over-reporters) for comparison. We considered the differences between the distribution with and without under- and over-reporters negligible and small enough to include identified under- and over-reporters in the modeling. All results presented from now are thus based on the 2,811 individuals from DANSDA. A comparison of the OIM distribution for the weekly consumption of fish, total red and processed meat, red meat and processed meat with and without under- and over-reporters is shown in Supplemental Material 5.

\subsection{Substitution model}

Only a small proportion of the Danish population reached the Danish FBDGs on fish and meat (Table 2). $77 \%$ had an intake of fish below the recommended minimum $350 \mathrm{~g} /$ week and $67 \%$ had an intake of red and processed meat above the recommended maximum $500 \mathrm{~g} /$ week before substitution. $43 \%$ of the total number of individual days was subject to substitution and $40 \%$ of these were new fish consumption days. The target of at least $70 \%$ of the population reaching the dietary guideline for fish after substitution was achieved, while $50 \%$ of the population reached the dietary guideline for red and processed meat after substitution (Table 2). 


\begin{tabular}{|c|c|c|c|c|}
\hline & \multicolumn{2}{|c|}{ Reference scenario } & \multicolumn{2}{|c|}{ Alternative scenario } \\
\hline & $\mathbf{N}$ & $\%$ & $\mathbf{N}$ & $\%$ \\
\hline Individuals in sample population & 2,811 & - & - & - \\
\hline No. of individual days & 19,677 & - & - & - \\
\hline Individuals w. weekly fish intake $<350 \mathrm{~g}$ & 2,177 & 77 & 820 & 29 \\
\hline Individuals w. weekly meat intake $>500 \mathrm{~g}$ & 1,888 & 67 & 1,393 & 50 \\
\hline Individuals w. fish cons. freq. $\geq 3$ days/week & 1,741 & 62 & 2,702 & 96 \\
\hline Zero fish consumption days & 10,586 & 54 & 7,228 & 37 \\
\hline Zero meat consumption days & 2,013 & 10 & 5,259 & 27 \\
\hline Zero poultry consumption days & 13,019 & 66 & 14,165 & 72 \\
\hline Total substitution days (increased fish intake) & - & - & 8,408 & 43 \\
\hline New fish consumption days & & - & 3,358 & 17 \\
\hline
\end{tabular}

Table 2 Substitution statistics on observed individual intakes

The substitution of red and processed meat by fish caused a shift of the respective intake distributions; the distribution of fish consumption was shifted to the right while the distribution of total meat consumption was shifted to the left after substitution (Table 3). The current average weekly consumption of fish is $229.5 \mathrm{~g} /$ week, and below the recommended minimum of $350 \mathrm{~g} / \mathrm{week}$. After substitution, the consumption more than doubled to $747.2 \mathrm{~g} /$ week. The current average weekly consumption of red and processed meat is $597.9 \mathrm{~g} /$ week and therefore above the recommended maximum of $500 \mathrm{~g} /$ week. The median consumption of red and processed meat fell just below the recommended maximum consumption after substitution (496.3 g/week), however, the average was still above (594.5 g/week) (Table 3). 
Observed individual mean weekly consumption before and after substitution (g/week)

\begin{tabular}{|l|l|l|l|l|l|l|l|l|}
\hline & Mean & SD & P2.5 & P10 & P50 & P90 & P97.5 \\
\hline Fish & & & & & & & & \\
Scenario & & & & & & & & \\
\hline Current intake & 229.5 & 225.7 & 0.0 & 3.8 & 174.0 & 535.0 & 818.6 \\
\hline Alternative & 597.9 & 423.2 & 142.0 & 226.9 & 485.5 & $1,096.5$ & $1,701.7$ \\
scenario & & & & & & & & \\
\hline Red and processed
\end{tabular}

Red and processed meat

\begin{tabular}{|l|l|l|l|l|l|l|l|}
\hline Current intake & 747.2 & 452.8 & 127.1 & 278.4 & 653.5 & $1,327.5$ & $1,891.7$ \\
scenario & & & & & & & \\
\hline Alternative \\
scenario
\end{tabular}

\section{Red meat}

\begin{tabular}{|c|c|c|c|c|c|c|c|}
\hline $\begin{array}{l}\text { Current intake } \\
\text { scenario }\end{array}$ & 522.5 & 326.8 & 64.9 & 173.0 & 465.0 & 931.2 & $1,316.3$ \\
\hline $\begin{array}{l}\text { Alternative } \\
\text { scenario }\end{array}$ & 410.3 & 299.0 & 20.2 & 95.9 & 350.11 & 790.8 & $1,178.9$ \\
\hline
\end{tabular}

Processed Meat

\begin{tabular}{|l|l|l|l|l|l|l|l|}
\hline Current intake & 224.7 & 223.4 & 0.0 & 26.9 & 158.6 & 495.0 & 838.8 \\
scenario & & & & & & & \\
\hline Alternative & 184.1 & 203.8 & 0.0 & 12.0 & 120.6 & 431.0 & 747.2 \\
scenario & & & & & & & \\
\hline
\end{tabular}




\begin{tabular}{|c|c|c|c|c|c|c|c|}
\hline Poultry & & & & & & & \\
\hline $\begin{array}{l}\text { Current intake } \\
\text { scenario }\end{array}$ & 142.3 & 173.6 & 0.0 & 0.0 & 95.7 & 341.4 & 570.9 \\
\hline $\begin{array}{l}\text { Alternative } \\
\text { scenario }\end{array}$ & 116.9 & 157.3 & 0.0 & 0.0 & 67.3 & 297.1 & 500.5 \\
\hline
\end{tabular}

Table 3 Observed individual mean weekly consumption amounts of fish, total red and processed meat, red mean, processed meat, and poultry ( $\mathrm{g} /$ week) for 2,811 individuals from DANSDA ( $\geq 15$ years) before and after substitution. Abbreviations: P2.5: $2.5^{\text {th }}$ percentile; P10: $10^{\text {th }}$ percentile; P50: 50 ${ }^{\text {th }}$ percentile (median); P90: $90^{\text {th }}$ percentile; P97.5: $97.5^{\text {th }}$ percentile; SD: standard deviation.

The substitution increased fish consumption at the individual-day level in terms of frequency and amount (Figure 2 and Figure 3). The total number of zero fish consumption days decreased after substitution, as illustrated by the change in the height of the spike on the left-hand side of the two histograms in Figure 2. 

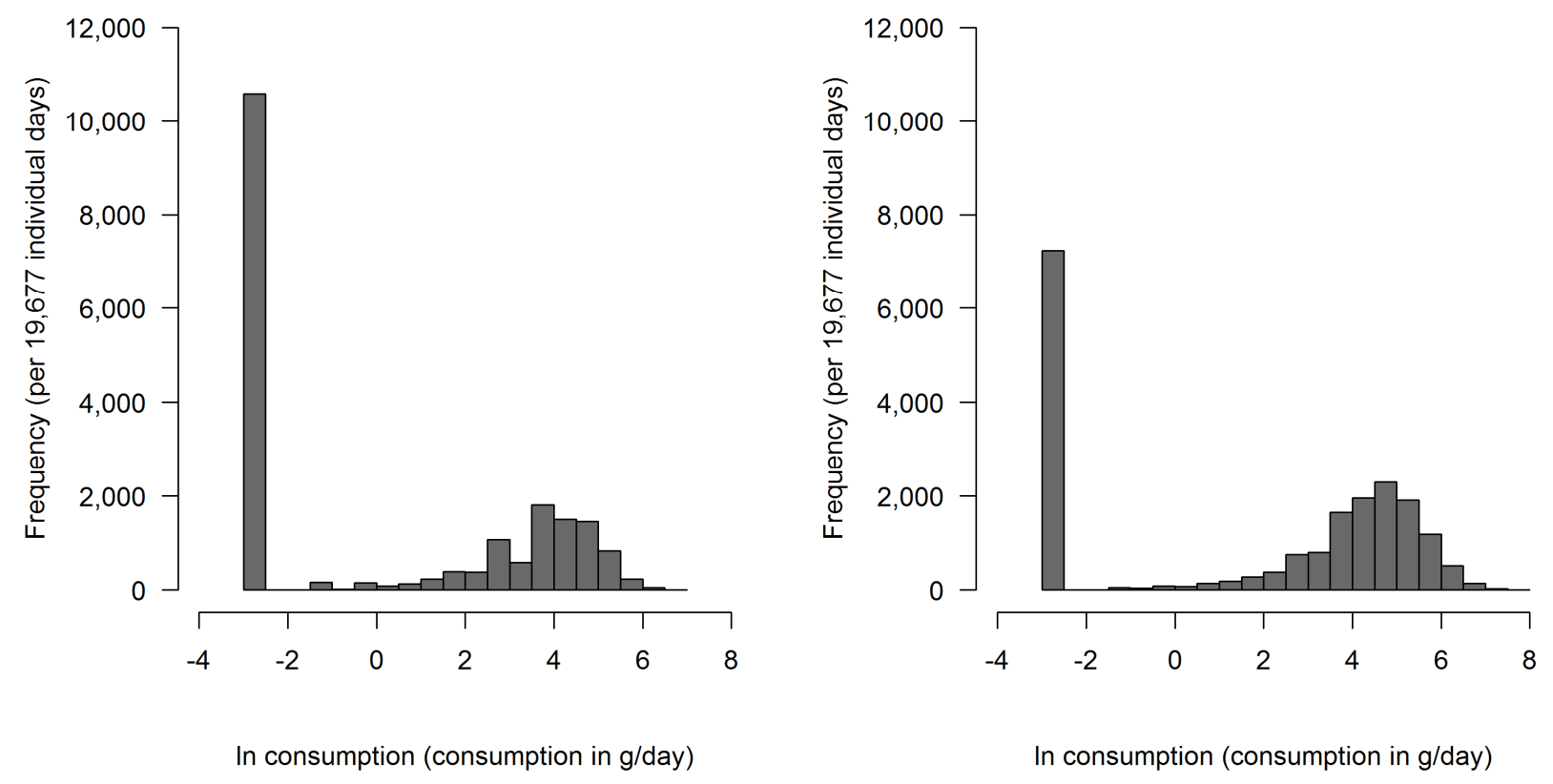

Figure 2 Individual-day fish consumption before and after substitution. Histograms showing the log daily intakes of fish in the Danish adult population (15-75 years, $n=19,677$ individual days) before (left) and after (right) the substitution. The large bar to the left in both histograms indicates the proportion of zero consumption days in the two scenarios.

The substitution caused an increase in the median fish consumption frequency from 3 days/week to 4 days/week (Figure 3, left), while the percentage of individual non-zero fish consumption days with higher intake amounts also increased (Figure 3, right). 

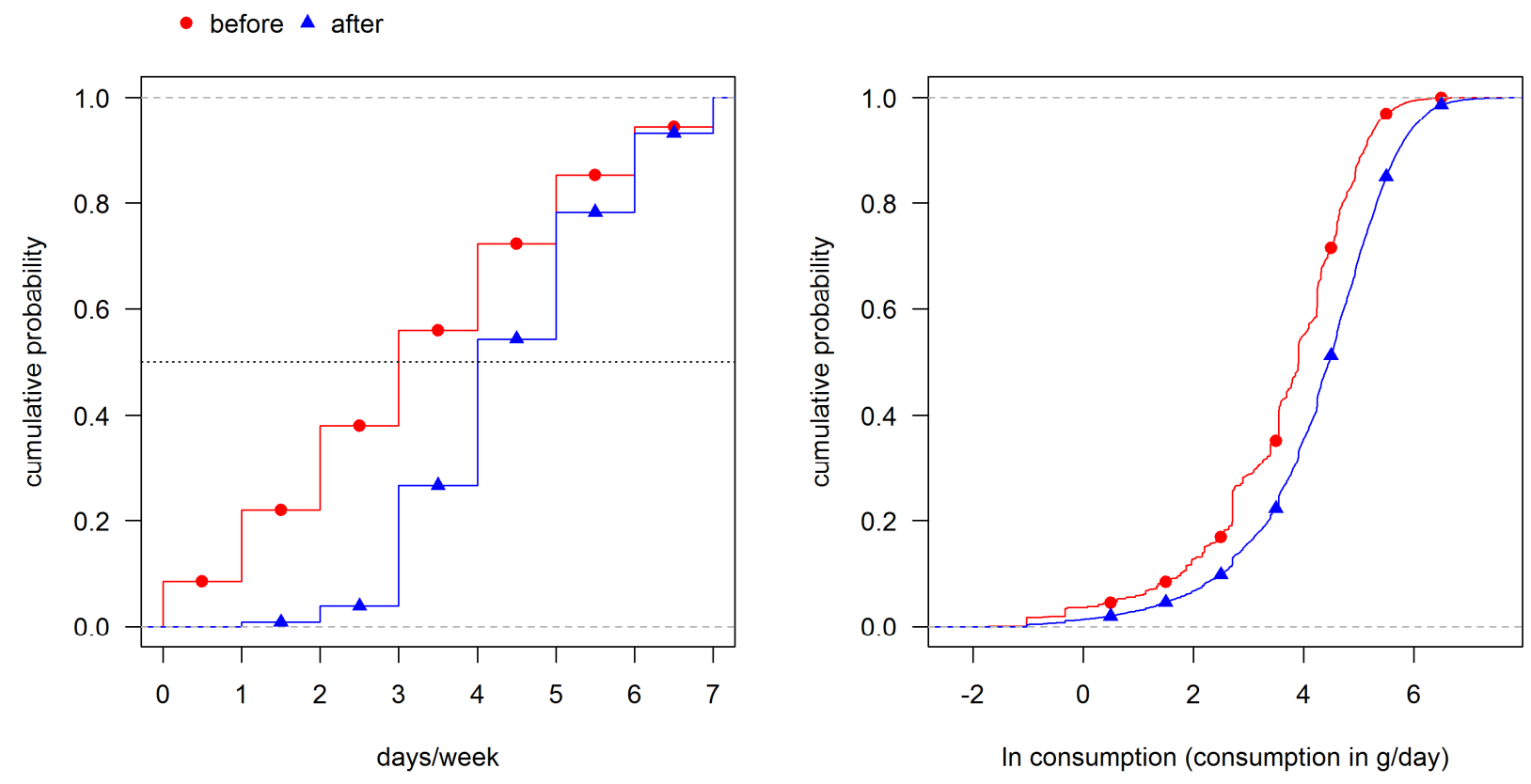

Figure 3 Observed fish consumption frequencies and weekly non-zero fish consumption amounts.

Empirical cumulative density function of the observed fish consumption frequency and individual-day nonzero fish consumption amounts on individual days before and after the substitution in the Danish adult population (15-75 years). Individual observed fish consumption frequencies are shown in the left plot and non-zero fish consumption amounts in the right plot, before (red dots) and after (blue triangles) the substitution. Frequency is given in days/week and amounts are log-transformed non-zero daily consumption amounts (consumption in $\mathrm{g} /$ day) using the natural logarithm. The dotted line in the left plot indicates the median frequency.

The substitution caused a decrease in the median meat consumption frequency from 7 days/week to 5 days/week due to the increased fish consumption (Figure 4, left), and the individual-day meat consumption amounts decreased (Figure 4, right). 

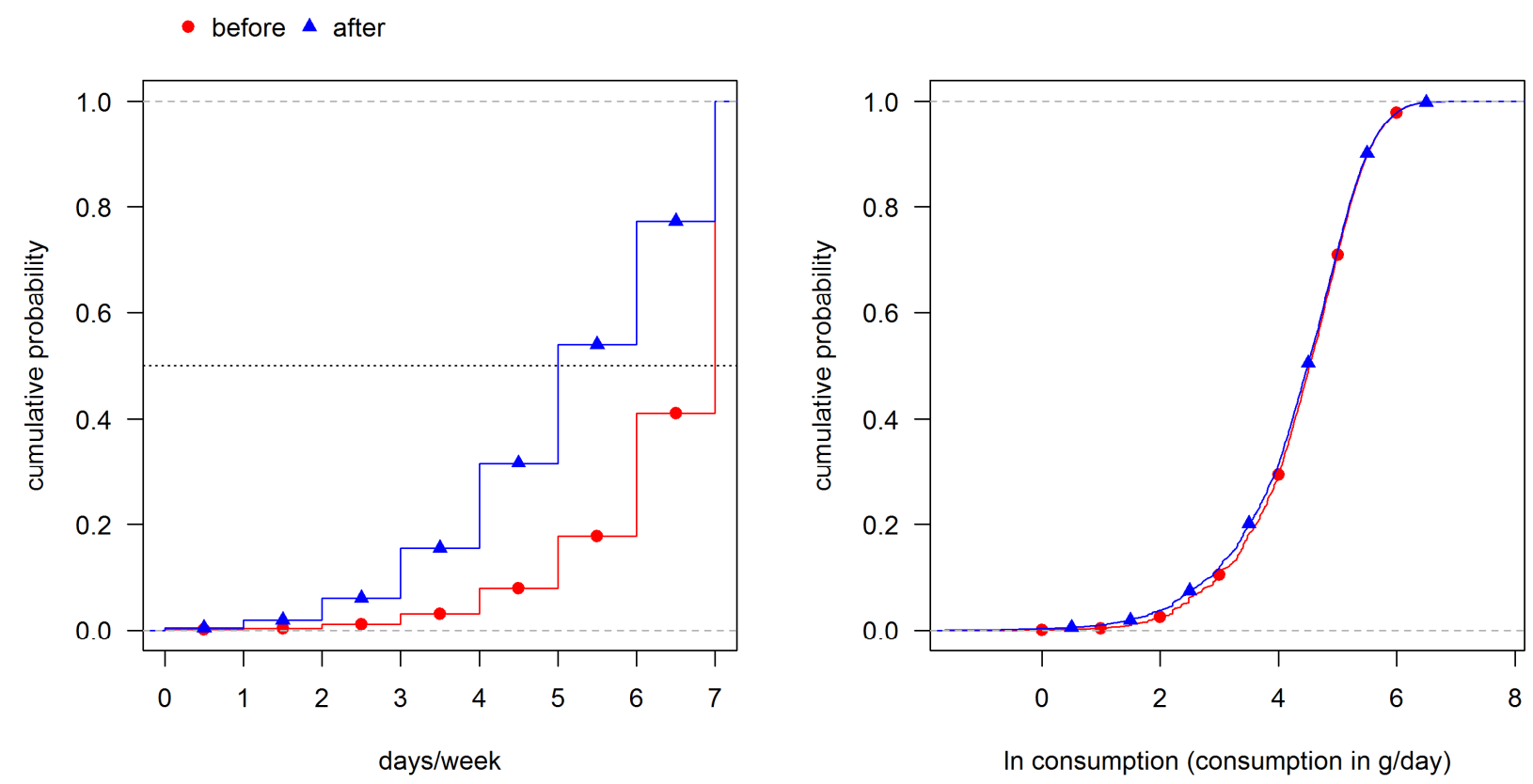

Figure 4 Observed meat consumption frequencies and weekly non-zero meat consumption amounts.

Empirical cumulative density function of the observed total meat consumption frequency and total meat nonzero consumption amounts on individual days before and after the substitution in the Danish adult population (15-75 years). Individual observed total meat consumption frequencies are shown in the left plot and nonzero amounts in the right plot, before (red dots) and after (blue triangles) the substitution. Frequency is given in days/week and amounts are log-transformed non-zero daily consumption amounts (consumption in g/day) using the natural logarithm. The dotted line in the left plot indicates the median frequency.

The increases in individual total weekly fish consumption amounts are illustrated in the left panel of Figure 5. The decrease in consumption of red and processed meat is shown in the right panel of Figure 5, although less pronounced than the increase in fish consumption. 

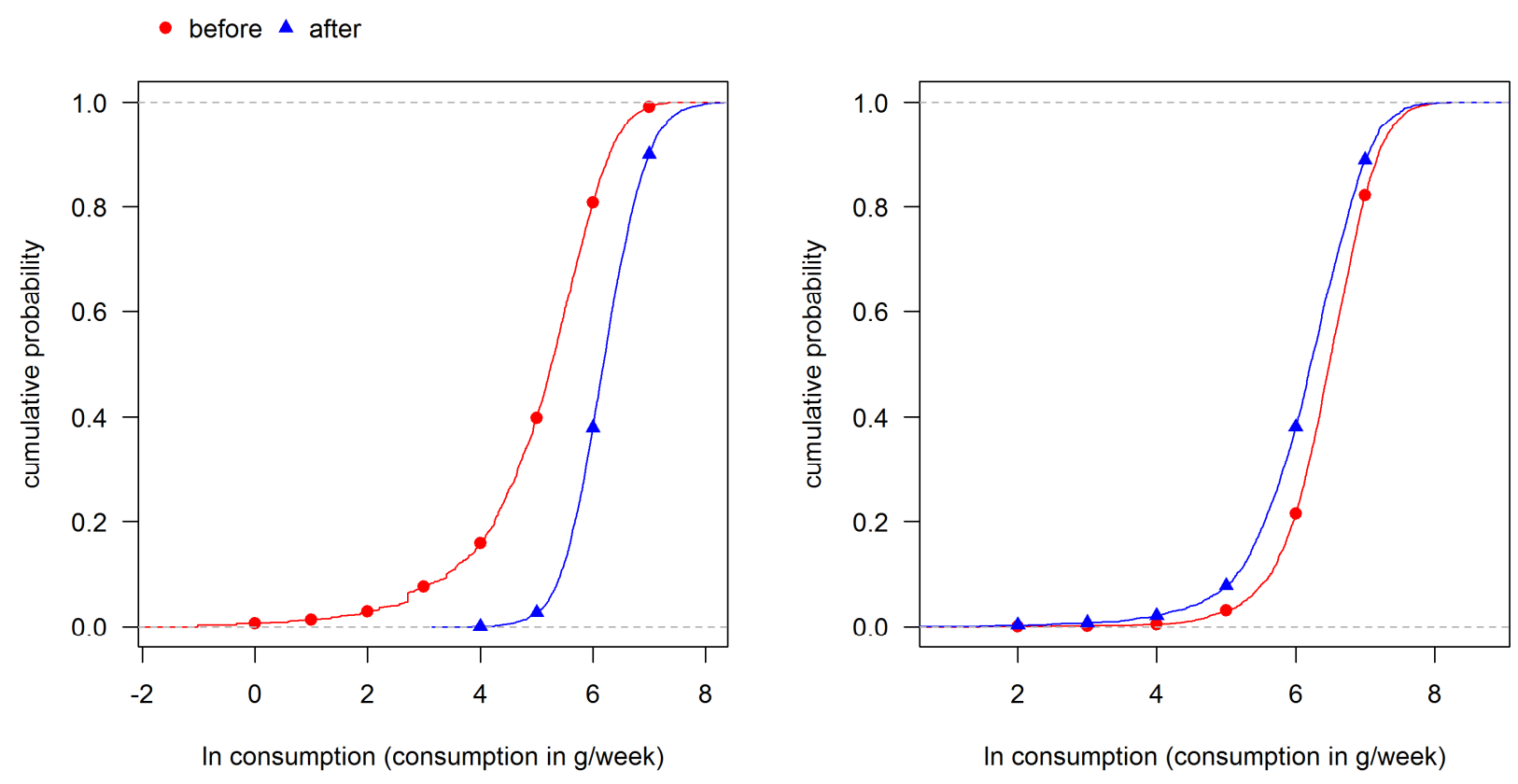

Figure 5 Weekly non-zero fish and meat consumption amounts. Empirical cumulative density functions of log non-zero weekly fish (left) and meat (right) consumption amounts before (red dots) and after (blue triangles) the substitution in the Danish adult population (15-75 years). Amounts are log-transformed nonzero weekly consumption amounts (consumption in $\mathrm{g} /$ week) using the natural logarithm.

\subsection{Usual intake model}

We compared the proposed four-part UID with the OIM model. We found that applying the fourpart UID model on the intake data caused a shrinkage of the distribution of individual usual intakes towards the mean compared to the distribution of individual OIM intakes (Table 4). This shrinkage was observed in the usual intake in the reference scenario, the intake difference between the reference and alternative scenario, and thus also in the intake in the alternative scenario. Like the LNN model, the mean of the four-part UID and OIM distributions were very similar. Non-normal 
behavior was observed for some foods and food components when applying the four-part UID

model on the transformed observed individual-day intakes/intake ratios. In these cases, we applied the OIM to model the usual intakes/usual intake differences (Supplemental Material 9).

\begin{tabular}{|l|l|l|l|l|l|l|l|l|}
\hline & Mean & SD & P2.5 & P10 & P50 & P90 & P97.5 \\
\hline Fish (g/day) & 28.70 & 29.98 & 0.00 & 0.00 & 20.45 & 67.60 & 105.93 \\
\hline Reference OIM & 28.89 & 26.08 & 0.00 & 0.00 & 21.95 & 62.78 & 97.36 \\
\hline Reference UID & & & & & & \\
\hline Substitution OIM & 84.81 & 59.37 & 20.26 & 32.61 & 69.90 & 153.35 & 244.49 \\
\hline Substitution UID & 84.47 & 44.76 & 26.34 & 40.79 & 74.04 & 133.48 & 203.71 \\
\hline Difference OIM & 56.11 & 61.79 & 0.00 & 0.00 & 40.38 & 128.19 & 220.08 \\
\hline Difference UID & 55.58 & 47.78 & 0.00 & 0.00 & 49.89 & 107.53 & 165.49 \\
\hline DHA + EPA (mg/day) & & & & & & \\
\hline Reference OIM & 342.76 & 464.19 & 0.00 & 0.00 & 174.79 & 909.94 & $1,624.48$ \\
\hline Reference UID & 337.38 & 411.66 & 0.00 & 0.00 & 194.32 & 851.7 & $1,483.46$ \\
\hline Substitution OIM & 979.42 & 866.12 & 120.38 & 241.11 & 741.41 & $1,982.48$ & $3,478.92$ \\
\hline Substitution UID & 956.37 & 631.38 & 211.04 & 368.06 & 834.70 & $1,586.79$ & $2,669.87$ \\
\hline Difference OIM & 636.66 & 821.82 & 0.00 & 0.00 & 383.89 & $1,547.77$ & $3,050.71$ \\
\hline Difference UID & 618.99 & 590.97 & 0.00 & 0.00 & 556.46 & $1,140.83$ & $2,154.77$ \\
\hline $\begin{array}{l}\text { MeHg ( } \mu \text { g/kg bw/day) } \\
\text { Reference OIM }\end{array}$ & 0.031 & 0.044 & 0.00 & 0.00 & 0.018 & 0.071 & 0.14 \\
\hline Reference UID & 0.029 & 0.028 & 0.00 & 0.00 & 0.022 & 0.061 & 0.096 \\
\hline Substitution OIM & 0.087 & 0.092 & 0.012 & 0.021 & 0.057 & 0.19 & 0.34 \\
\hline & & & & & & \\
\hline
\end{tabular}




\begin{tabular}{|c|c|c|c|c|c|c|c|}
\hline Substitution UID & 0.084 & 0.074 & 0.020 & 0.034 & 0.064 & 0.15 & 0.32 \\
\hline Difference OIM & 0.057 & 0.079 & 0.00 & 0.00 & 0.032 & 0.15 & 0.28 \\
\hline Difference UID & 0.055 & 0.069 & 0.00 & 0.00 & 0.041 & 0.11 & 0.27 \\
\hline \multicolumn{8}{|c|}{ Dioxin + dl-PCBs (pg TEQ/kg bw/day) } \\
\hline Reference OIM & 0.68 & 0.46 & 0.19 & 0.28 & 0.57 & 1.21 & 1.78 \\
\hline Reference UID & 0.68 & 0.34 & 0.23 & 0.34 & 0.61 & 1.10 & 1.55 \\
\hline Substitution OIM & 1.17 & 0.77 & 0.38 & 0.51 & 0.98 & 2.01 & 3.09 \\
\hline Substitution UID & 1.12 & 0.59 & 0.41 & 0.57 & 0.98 & 1.80 & 2.66 \\
\hline Difference OIM & 0.49 & 0.68 & 0.00 & 0.00 & 0.28 & 1.23 & 2.31 \\
\hline Difference UID & 0.44 & 0.52 & 0.00 & 0.00 & 0.31 & 1.03 & 1.78 \\
\hline \multicolumn{8}{|c|}{ Processed meat (g/day) } \\
\hline Reference OIM & 32.95 & 33.32 & 0.00 & 3.73 & 22.90 & 74.42 & 121.42 \\
\hline Reference UID & 32.54 & 29.47 & 0.00 & 5.63 & 23.89 & 71.88 & 108.56 \\
\hline Substitution OIM & 26.81 & 30.49 & 0.00 & 1.71 & 16.81 & 64.24 & 108.21 \\
\hline Substitution UID & 26.48 & 26.07 & 0.00 & 2.81 & 17.66 & 62.91 & 98.09 \\
\hline Difference OIM & -6.13 & 8.62 & -29.24 & -15.64 & -3.55 & 0.00 & 0.00 \\
\hline Difference UID & -6.07 & 7.55 & -26.16 & -14.77 & -4.11 & 0.00 & 0.00 \\
\hline \multicolumn{8}{|l|}{ Red meat (g/day) } \\
\hline Reference OIM & 73.64 & 46.12 & 9.05 & 24.34 & 65.82 & 130.42 & 183.01 \\
\hline Reference UID & 74.37 & 33.06 & 19.78 & 35.87 & 71.86 & 116.14 & 149.88 \\
\hline Substitution OIM & 56.94 & 42.42 & 1.40 & 13.40 & 47.23 & 110.69 & 163.54 \\
\hline Substitution UID & 57.61 & 31.60 & 6.08 & 21.68 & 52.45 & 100.36 & 130.89 \\
\hline Difference OIM & -16.70 & 20.45 & -69.76 & -40.43 & -10.54 & 0.00 & 0.00 \\
\hline
\end{tabular}




\begin{tabular}{|c|c|c|c|c|c|c|c|}
\hline Difference UID & -16.76 & 17.10 & -58.80 & -38.97 & -13.08 & 0.00 & 0.00 \\
\hline \multicolumn{8}{|l|}{ Iron (mg/day) } \\
\hline Reference OIM & 11.04 & 3.81 & 4.92 & 6.66 & 10.59 & 15.72 & 19.61 \\
\hline Reference UID & 11.04 & 3.47 & 5.35 & 6.97 & 10.67 & 15.38 & 18.80 \\
\hline Substitution OIM & 10.89 & 3.74 & 5.03 & 6.65 & 10.44 & 15.52 & 19.34 \\
\hline Substitution UID & 10.95 & 3.43 & 5.32 & 6.99 & 10.59 & 15.20 & 18.74 \\
\hline Difference OIM & -0.15 & 0.47 & -1.32 & -0.63 & -0.060 & 0.22 & 0.72 \\
\hline Difference UID & -0.096 & 0.46 & -1.20 & -0.57 & 0.00 & 0.31 & 0.60 \\
\hline \multicolumn{8}{|l|}{ Vitamin D ( $\mu g /$ day $)$} \\
\hline Reference OIM & 4.22 & 3.72 & 0.94 & 1.35 & 2.98 & 8.72 & 14.51 \\
\hline Reference UID & 3.94 & 2.21 & 1.32 & 1.85 & 3.45 & 6.67 & 9.35 \\
\hline Substitution OIM & 7.37 & 5.87 & 1.90 & 2.63 & 5.66 & 13.94 & 23.75 \\
\hline Substitution UID & 7.03 & 4.63 & 2.44 & 3.25 & 5.93 & 11.34 & 19.37 \\
\hline Difference OIM & 3.15 & 4.89 & 0.00 & 0.00 & 1.62 & 7.58 & 15.80 \\
\hline Difference UID & 3.09 & 4.40 & 0.00 & 0.00 & 1.80 & 7.00 & 14.41 \\
\hline \multicolumn{8}{|l|}{ Energy (kJ/day) } \\
\hline Difference OIM & 110.24 & 373.48 & -417.69 & -163.67 & 25.88 & 459.87 & $1,172.80$ \\
\hline Difference UID & 110.24 & 373.48 & -417.69 & -163.67 & 25.88 & 459.87 & $1,172.80$ \\
\hline
\end{tabular}

Table 4 Observed individual mean intake compared to four-part UID intake for the 100,000 individuals (15-

75 years) simulated from the Danish National Survey of Diet and Physical Activity using sampling weights.

Only foods and food components that were associated with a health effect were modeled. Abbreviations: dl-

PCB: dioxin-like polychlorinated biphenyls; DHA: docosahexaenoic acid; EPA: eicosapentaenoic acid;

MeHg: methyl mercury; OIM: observed individual mean; P2.5: $2.5^{\text {th }}$ percentile; P10: $10^{\text {th }}$ percentile; P50:

$50^{\text {th }}$ percentile; P90: $90^{\text {th }}$ percentile; $\mathrm{P} 97.5$ : $97.5^{\text {th }}$ percentile; SD: standard deviation; TEQ: toxic equivalents;

UID: usual intake difference. 
The difference in usual intakes before and after substitution for the foods (fish, red meat, and processed meat) and food components (DHA and EPA, MeHg, and dioxin and dl-PCBs), modeled by the four-part UID model and used for the DALY calculations are illustrated in Figure 6. 

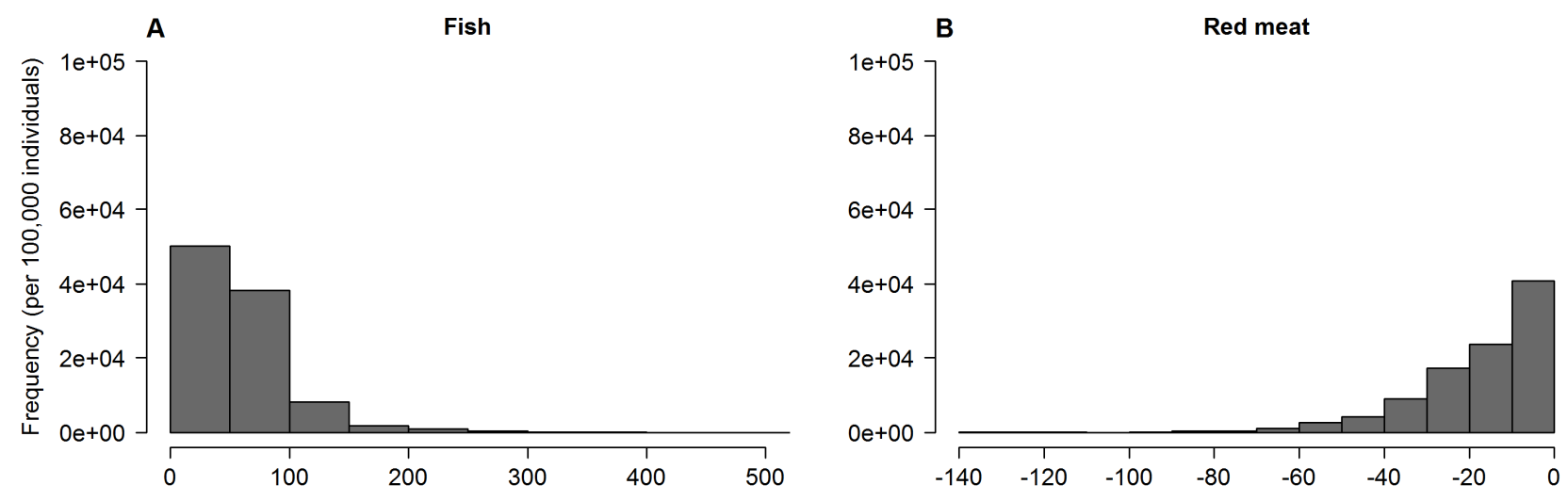

consumption change (g/day)

consumption change (g/day)
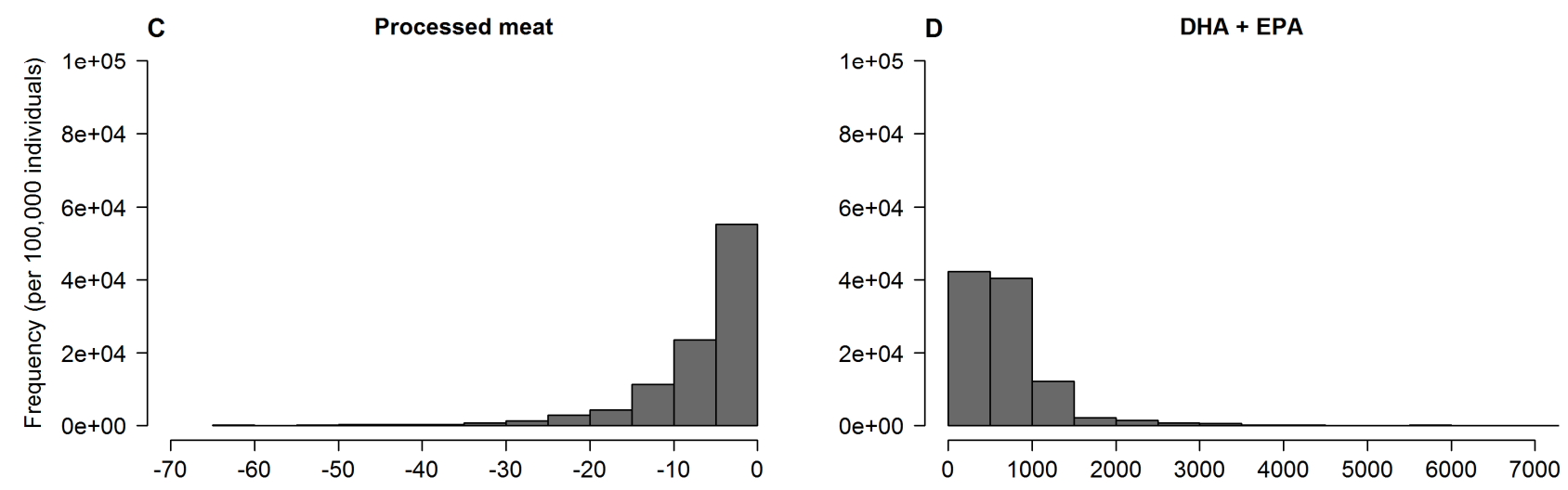

consumption change (g/day)

intake change (mg/day)
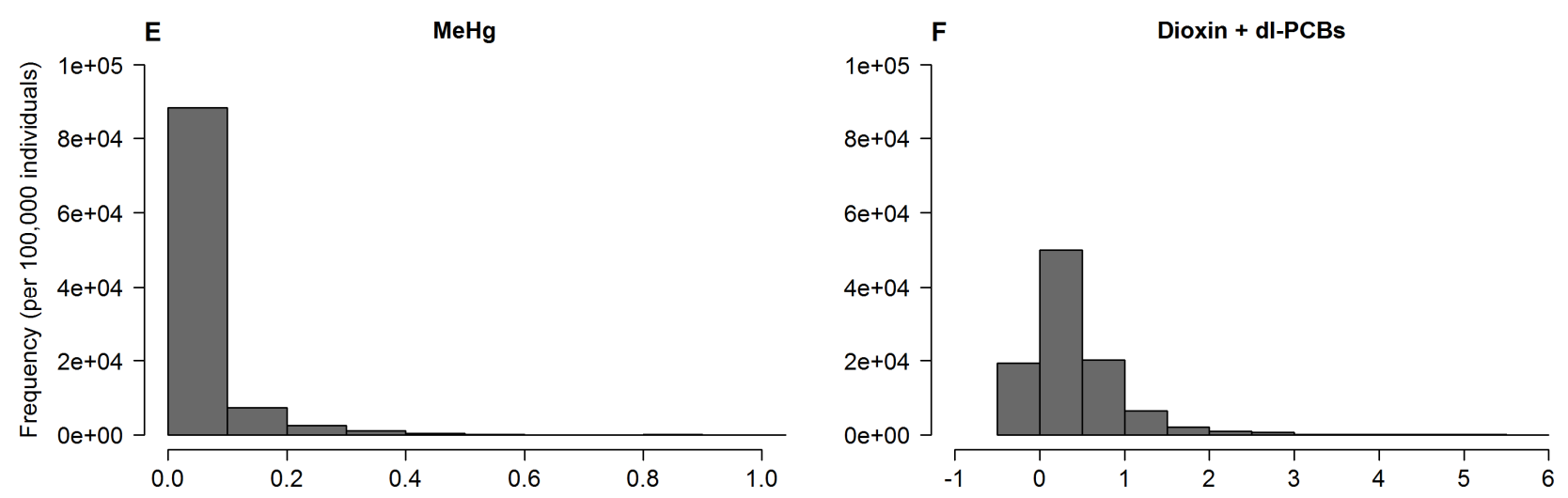

exposure change ( $\mu \mathrm{g} / \mathrm{kg}$ bw/day)

exposure change (pg TEQ/kg bw/day)

Figure 6 Differences in usual intake. Individual differences in usual intake between the reference and alternative scenario, as modeled by the four-part UID model. The histograms show differences in usual 
intake for A) fish, B) red meat, C) processed meat, D) docosahexaenoic acid (DHA) and eicosapentaenoic acid (EPA), E) methyl mercury (MeHg), and F) dioxin and dioxin-like polychlorinated biphenyls (dl-PCBs).

\subsection{Comparison with health-based guidance values and dietary reference values}

Based on the usual intake distributions, we found an increase in the proportion of individuals exceeding the TWI for MeHg (from $0.3 \%$ to $6.0 \%$ ) and for dioxin + dl-PCBs (from $0.5 \%$ to $7.0 \%$ ) (Table 5). However, whereas no or only very small changes were observed in the proportion of individuals below the AR for iron, a marked decrease in the proportion of individuals below the AI for DHA + EPA (from $58.0 \%$ to $4.0 \%$ ) and below the AR for vitamin D (from 94\% to 69\%) was observed (Table 5).

We also investigated the change in energy intake due to the substitution. Approximately $80 \%$ of all 100,000 simulated individuals experienced an increase in usual energy intake. The mean change in usual energy intake was $110.24 \mathrm{~kJ} /$ day, summing to $772 \mathrm{~kJ}$ extra/week.

\begin{tabular}{|c|c|c|c|c|c|c|c|}
\hline Scenario & $\begin{array}{l}\mathrm{MeHg} \\
\%>\mathrm{TWI}\end{array}$ & $\begin{array}{l}\text { Dioxin + } \\
\text { dl-PCBs } \\
\%>\text { TWI }\end{array}$ & $\begin{array}{l}\mathrm{DHA}+ \\
\mathrm{EPA} \\
\%<\mathrm{AI}\end{array}$ & $\begin{array}{l}\text { Vitamin } \\
\text { D } \\
\%<\mathrm{AR}\end{array}$ & $\begin{array}{l}\text { Iron } \\
\%<\mathrm{AR} \\
\text { (men) }\end{array}$ & $\begin{array}{l}\text { Iron } \\
\%<\mathrm{AR} \\
\text { (women }> \\
49 \text { years) }\end{array}$ & $\begin{array}{l}\text { Iron } \\
\%<\mathrm{AR} \\
\text { (women } 15 \\
-49 \text { years) }\end{array}$ \\
\hline Reference & 0.3 & 0.5 & 58.0 & 94.0 & 5.0 & 5.0 & 60.0 \\
\hline Alternative & 6.0 & 7.0 & 4.0 & 69.0 & 5.0 & 4.0 & 60.0 \\
\hline
\end{tabular}

Table 5 Proportions of the 100,000 simulated individuals ( $\geq 15$ years) above the tolerable weekly intake for methyl mercury (MeHg) and dioxin and dioxin-like (dl-) polychlorinated biphenyls (PCBs), below the recommended daily intake for docosahexaenoic acid (DHA) and eicosapentaenoic acid (EPA) and below the average requirement for vitamin D and iron. Abbreviations: AI: adequate intake; AR: average requirement; 
DHA: docosahexaenoic acid; dl-PCB: dioxin-like polychlorinated biphenyl; EPA: eicosapentaenoic acid; MeHg: methyl mercury; TWI: tolerable weekly intake.

${ }^{\mathrm{a}}$ The tolerable weekly intake for MeHg is $1.3 \mu \mathrm{g} / \mathrm{kg}$ bw/week (EFSA CONTAM Panel 2012).

${ }^{\mathrm{b}}$ The tolerable weekly intake for dioxin and dl-PCBs is $14 \mathrm{pg}$ TEQ/kg bw/week (Scientific Committee on Food 2001).

${ }^{\mathrm{c}}$ The adequate intake of DHA and EPA is $250 \mathrm{mg} /$ day (300 mg/day for pregnant/lactating women) (EFSA NDA Panel 2010a; FAO 2010).

${ }^{\mathrm{d}}$ The average requirement for vitamin D is $7.5 \mu \mathrm{g} /$ day (Nordic Council of Ministers 2014).

${ }^{\mathrm{e}}$ The average requirement for iron is $7 \mathrm{mg} /$ day for men, $6 \mathrm{mg} /$ day for postmenopausal women, and 10 $\mathrm{mg} /$ day for women in the fertile age (Nordic Council of Ministers 2014).

\subsection{Disability-Adjusted Life Years}

We found the substitution of red and processed meat with fish to be overall beneficial with 5,786 (95\% UI: 4,390; 7,299) DALYs averted each year due to the substitution on the level of the Danish population of age 15-75 years (approx. 4.3 million). The health gain was mainly explained by the increased fish consumption, with the effects on fetal neurodevelopment and fatal CHD contributing with $112(81 ; 146)$ DALYs averted per 100,000 (Table 6). The beneficial effects of fish consumption dominate over the adverse effects of $\mathrm{MeHg}$ on a population level. We estimated that 903 children $(1,172 ; 631)$ less per 100,000 would shift to a lower class of intellectual disability due to increased fish consumption of their mothers. The decrease in red and processed meat consumption contributed with $25(18 ; 32)$ DALYs averted per 100,000 to the overall DALY difference, mainly driven by the decreased risk of CRC. The adverse effects of dioxin compromised the overall beneficial health impact by only $2.5(0.3 ; 6.9)$ DALYs per 100,000 , although $122(6$, 323) extra cases of hypothyroidism were estimated due to increased dioxin exposure. The substitution of poultry was not found to introduce additional health effects. The DALY differences for all included health outcomes were significantly different from zero (pseudo p-value $<0.001$ ). 


\begin{tabular}{|l|l|l|l|}
\hline Food (component) & Health outcome & Extra cases/100,000 & $\Delta$ DALY/100,000 (95\% \\
\hline Fish (+ MeHg) & Fetal neurodevelopment & $-902.97(-1,171.51 ;-$ & UI) \\
\hline Fish (DHA + EPA) & Fatal CHD & $630.65)$ & $-48.42(-73.04 ;-30.05)$ \\
\hline Processed + red meat & CRC & $-2.13(-2.90 ;-1.45)$ & $-62.3(-84.97 ;-42.34)$ \\
\hline Processed meat & NCSC & $-3.40(-4.41 ;-2.47)$ & $-24.33(-31.61 ;-17.70)$ \\
\hline Fish + meat (dioxin + & Male infertility & $-0.047(-0.075 ;-0.017)$ & $-0.77(-1.22 ;-0.29)$ \\
\hline dl-PCBs) & & $0.64(0.00 ; 1.38)$ & $0.14(0.00 ; 0.37)$ \\
\hline Fish + meat (dioxin + & Hypothyroidism & $121.70(6.19 ; 322.98)$ & $2.30(0.12 ; 6.81)$ \\
\hline dl-PCBs) & & & \\
\hline Total & & & $\mathbf{- 1 3 4 . 1 5 ( - 1 6 9 . 2 1 ; - 1 0 1 . 7 7 )}$ \\
\hline
\end{tabular}

Table 6 Health impact of the substitution in terms of the difference in Disability-Adjusted Life Years between the alternative scenario and the current consumption by health outcome with the $95 \%$ uncertainty bounds in parenthesis. Abbreviations: CHD: coronary heart disease; CRC: colorectal cancer; DALY:

Disability-Adjusted Life Year; DHA: docosahexaenoic acid; dl-PCBs: dioxin-like polychlorinated biphenyls; EPA: eicosapentaenoic acid; MeHg: methyl mercury; NCSC: non-cardia stomach cancer; UI: uncertainty interval.

The distribution of individual total DALY differences, expressed in healthy life-days lost, is illustrated in Figure 7. The estimated individual healthy life-days lost are a measure for the average health impact for individuals of similar sex, age, and consumption habits. 


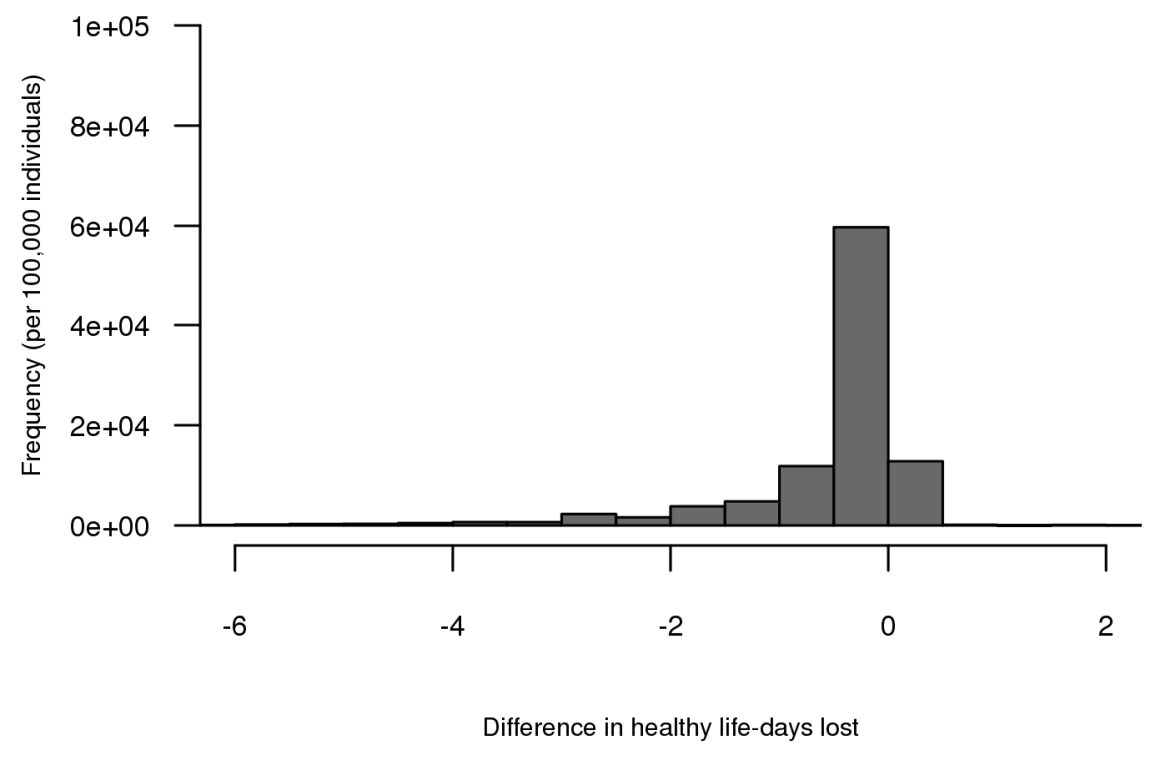

Figure 7 Individual health impact of the substitution. The individual health impact is expressed as the difference in healthy life-days lost between the reference and alternative scenario (all modeled causes).

The distributions of individual DALY differences per outcome are shown in Figure 8, expressed as healthy life-days lost. 

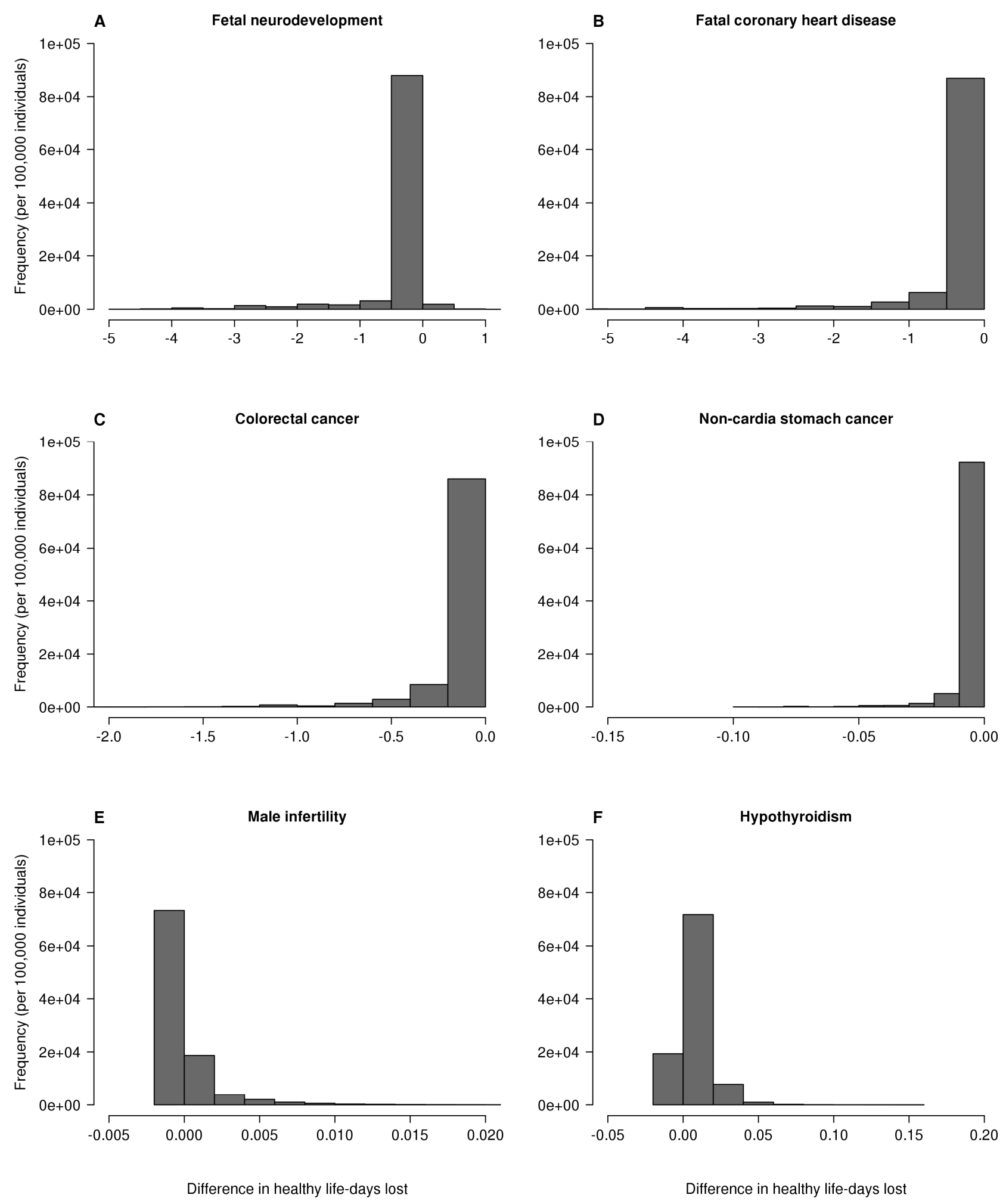

Figure 8 Individual health impact of the substitution by outcome. The individual health impact is expressed as the individual difference in healthy life-days lost between the reference and alternative scenario for A) fetal neurodevelopment, B) fatal coronary heart disease, C) colorectal cancer, D) non-cardia stomach 
cancer, E) male infertility, and F) hypothyroidism. Negative differences imply a health gain and positive differences imply a health loss.

We found the overall health impact of the substitution to vary largely by age and sex, and within subgroups (Figure 9, Figure 10). In particular, women in the childbearing age (in particular those between 25 and 40 years of age), men $>50$ years of age, and women $>60$ years of age experienced the highest health gains due to the substitution.

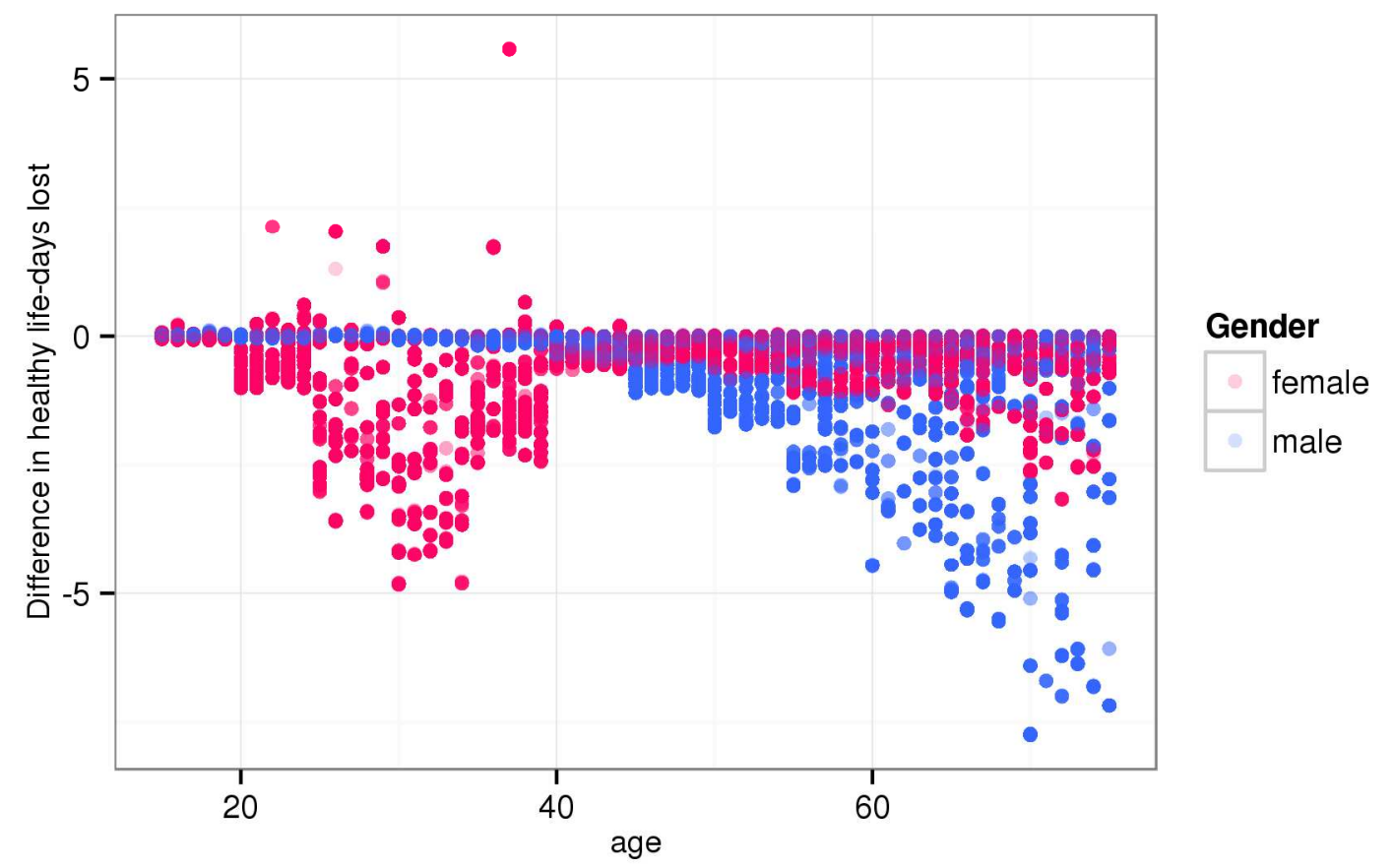

Figure 9 Total individual differences in healthy life-days lost by age and sex for the 100,000 simulated individuals. The individual health impact is expressed as the estimated individual difference in healthy lifedays lost between the reference and alternative scenario. Red dots represent women and blue dots represent men. Negative differences imply a health gain and positive differences imply a health loss. Age is given in years. 
The health impact experienced by different groups of age and sex varied by outcome, with the changes in risk of fatal CHD, CRC and NCSC having an impact mainly for men and elderly (Figure $10)$.

The health gain and loss of unborn children (fetal neurodevelopment and male infertility) were assigned their mothers (women of age 15-49 years). Finally, the increase in dioxin-induced hypothyroidism incidence was evenly distributed across sex and ages.

Our variable importance analysis showed that in general the uncertainty in the dose-response functions and relative risk estimates were the largest contributors to the overall uncertainty of the DALY difference estimates (CRC, NCSC, male infertility, and hypothyroidism) whereas for fetal neurodevelopment, the uncertainty in the DW for borderline intellectual disability contributed equally to the uncertainty as the dose-response for the beneficial effects of fish consumption. The dose-response function describing the adverse effects of $\mathrm{MeHg}$ on neurodevelopment only contributed little to the overall quantified uncertainty (Supplemental Material 11). 

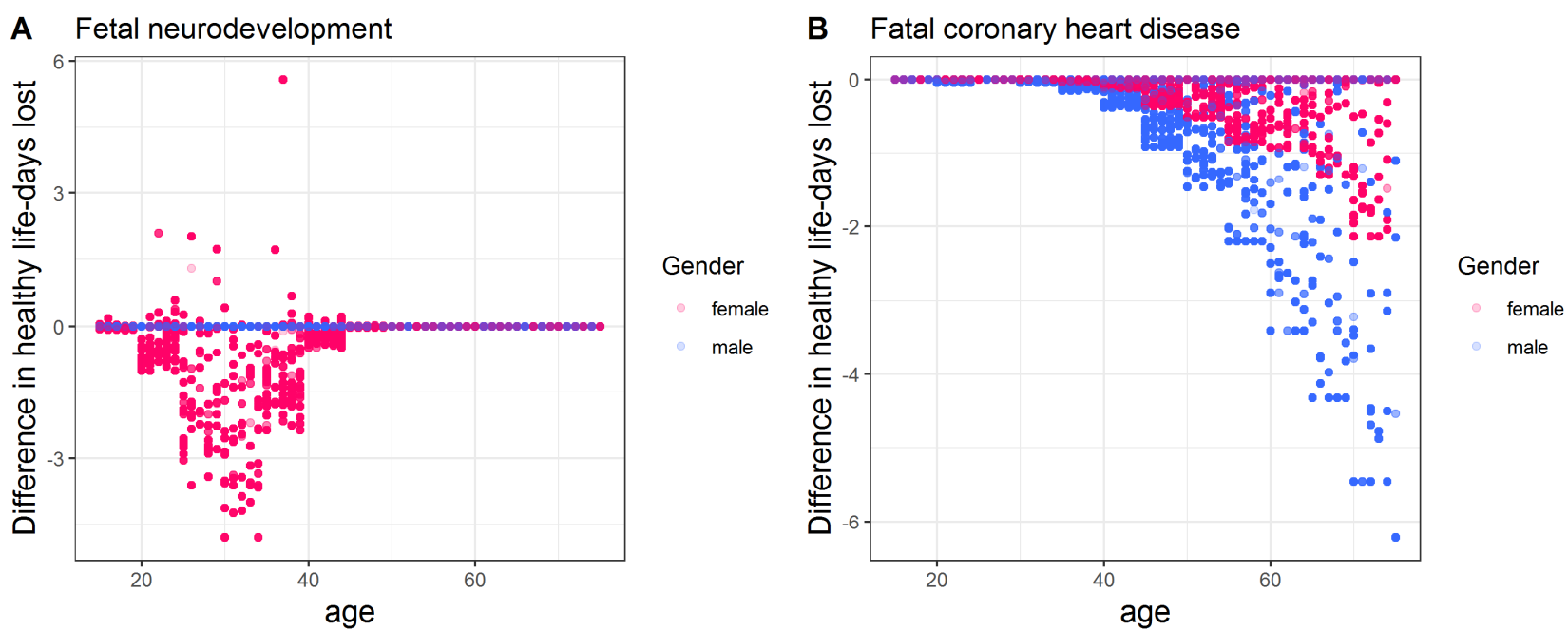

C Colorectal cancer

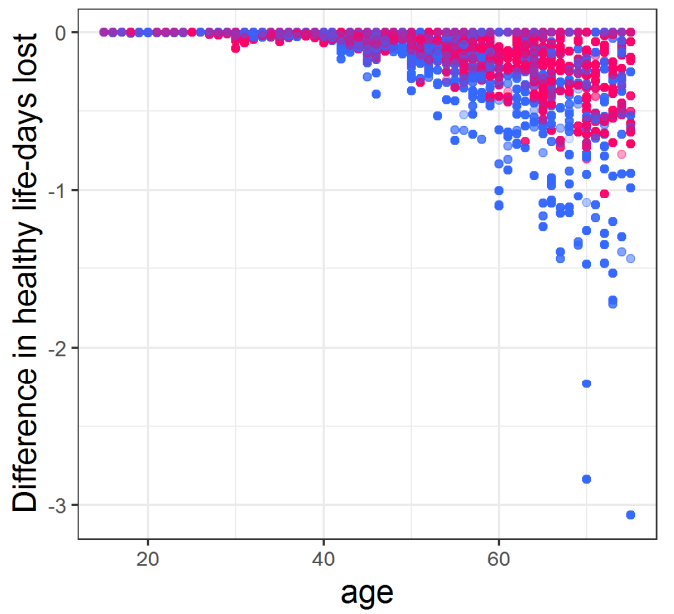

D Non-cardia stomach cancer

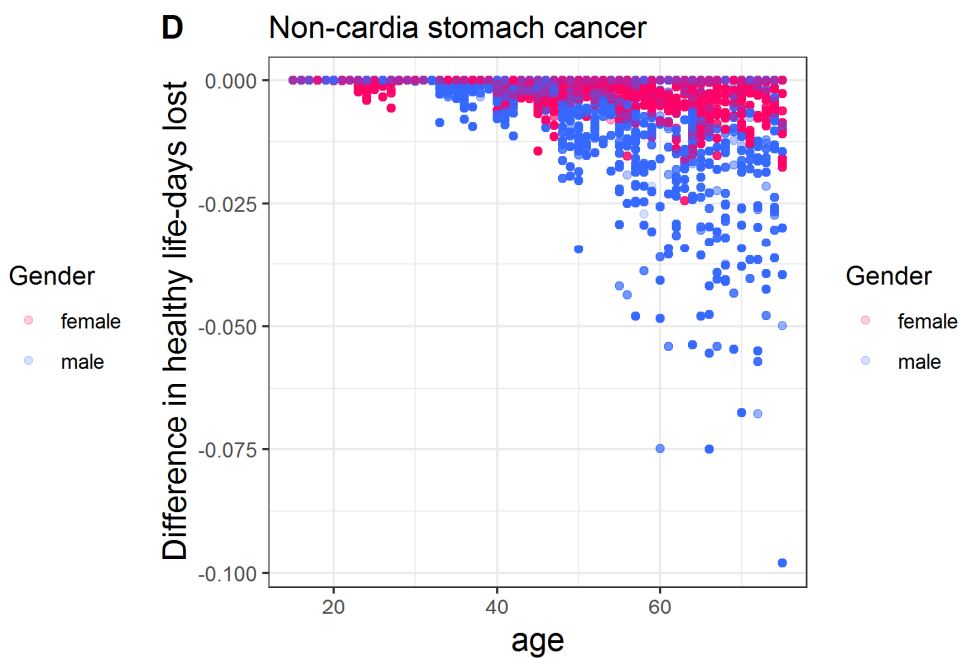

E Male infertility
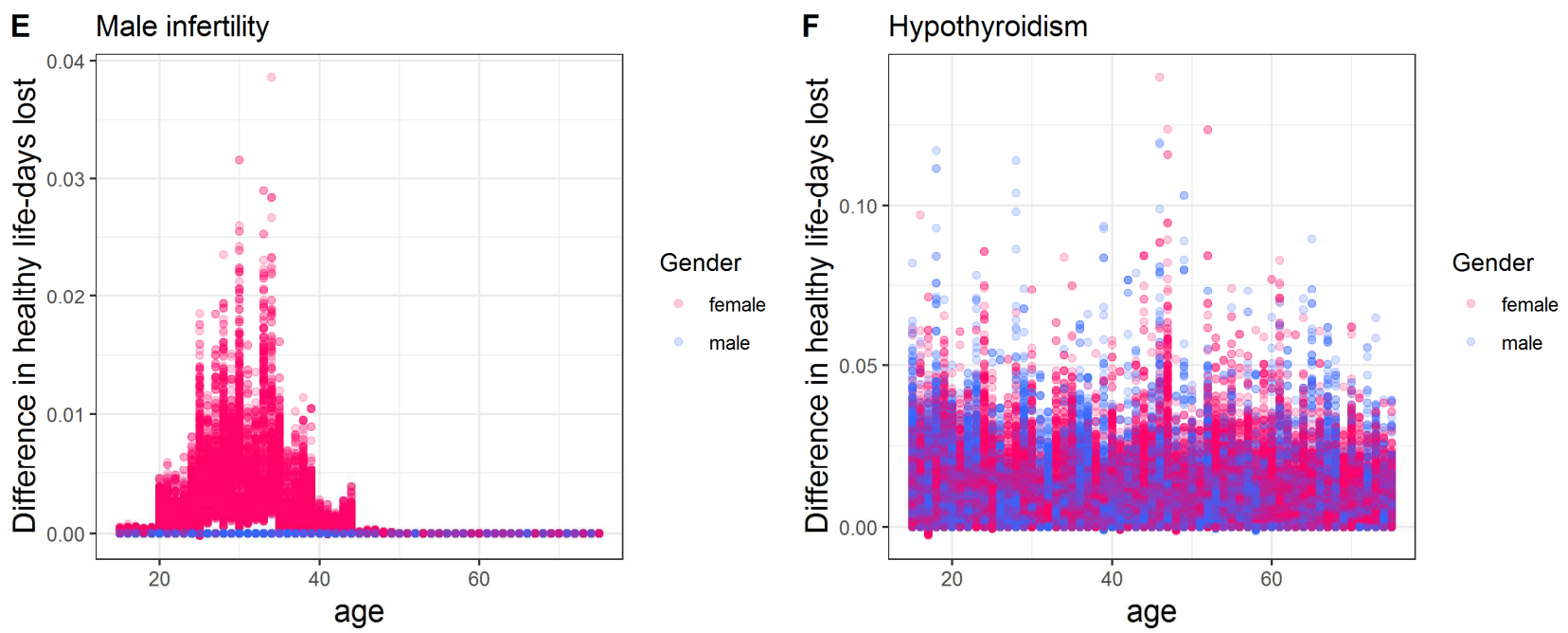

Figure 10 Individual differences in healthy life-days lost by outcome and age and sex. Individual

differences in healthy life-days lost by age and sex for the 100,000 simulated individuals for A) fetal neurodevelopment, B) fatal coronary heart disease, C) colorectal cancer, D) non-cardia stomach cancer, E) 
male infertility, and F) hypothyroidism. Red dots represent women and blue dots represent men. Negative differences imply a health gain and positive differences imply a health loss. Age is given in years.

\section{Discussion}

We assessed the variability in health gain and loss of substituting red and processed meat with fish in the Danish adult diet by accounting for variability in food substitution behavior and in health impact between individuals. Our results show that, overall, 134 (95\% UI: 102; 169)

DALYs/100,000 could be averted each year if the Danish adult population (15-75 years) substituted some of their consumption of red and processed meat with fish in order for $70 \%$ of the population to reach the recommended $350 \mathrm{~g}$ of fish/week. We found that the health impact varied largely between age and sex; women in the childbearing age (in particular those between 25 and 40 years of age), men $>50$ years of age, and women $>60$ years of age experienced the highest health gain due to the substitution. Thus, our results highlight the need and provide support for public health strategies and advice that are targeted to specific groups within the population.

We applied a probabilistic approach to the substitution modeling to reflect the potential variability in food substitution choices and consumption frequencies and amounts within the relevant food groups. We defined the target weekly fish consumption amount as a stochastic variable, building on the target of $70 \%$ of the Danish adult population reaching the recommended level of fish consumption. This approach took into account that not all individuals will reach the recommended level of fish consumption, which can be of valuable information for policy makers and is often taken into account in nutrition goals (Nordic Council of Ministers 2006). Furthermore, we adjusted the intake of the foods and food components considered for within-individual variability to estimate the usual (long-term) intakes. Building on an established usual intake model, we proposed an 
approach that allows for comparison of two or more intake distributions as needed for RBA studies, while keeping information on individual characteristics.

We assumed that our substitution model describes the expected changes in the population if the Danish adult population were to increase the intake of fish by substituting red and processed meat and/or poultry. We did not put any constraints on the choice of fish type in the substitution model, thus the choice of fish built on current probabilities of intake of a variety of currently consumed fish species reported in the Danish population, and the portion sizes were sampled from an empirical distribution of fish-type specific portion sizes. Thomsen et al. (2018) also investigated the substitution of red and processed meat with fish; however, the substitution model applied in that study assumed that all individuals would substitute in the same manner, considering only variability associated with the consumption at baseline. In the present study, we took variability in preferences for food types, portion sizes, and intake frequency into account. While our model suggests a potential substitution behavior in the Danish population, we emphasize that it is not based on predictions of substitution behavior. Although we acknowledge the potential differences in consumption behavior across subgroups in the population, differences in consumption behavior dependent on covariates such as age and sex were not taken into account in the substitution.

In this study, we propose an application of the established LNN model for adjustment of individual dietary intakes for within-individual variability when dealing with multiple intake scenarios. To our knowledge, this has not been addressed previously. We found that simply modeling the usual intakes in the two scenarios independently caused the individual intakes in the alternative scenario to be incoherent with the direction of the food changes forced by the substitution model. Indeed, individuals that were ascribed an increased fish consumption by the substitution model, had a decreased fish consumption after applying the LNN model on the intake in the alternative scenario, and vice versa for meat consumption. Modeling intake differences instead and combining it with the 
modeled usual intake in the reference scenario suggests a solution to modeling the individual usual intake in a comparative alternative scenario.

Our results show that the four-part UID distribution is narrower when compared to the OIM distribution. This is coherent with the behavior of the LNN model as found by previous studies on usual intake modeling (Goedhart et al. 2012; Slob 2006). The intake differences modeled in this study depended on both the intake in the reference scenario and the sampled individual target fish consumption and portion sizes. The within-individual variability in intake amounts in the reference scenario and in the sampled fish consumption portion sizes, based on the reference scenario, are transferred to the consumption in the alternative scenario. If the intake distributions were not adjusted for within-individual variability, we could overestimate the tails with the risk of estimating too many individuals with a very low intake of nutrients and too many individuals with a very high exposure to contaminants. While this may be considered a precautious approach in risk assessment, not adjusting for within-individual variability may give misleading estimates in RBA and burden of disease studies. We applied the OIM for modeling intake differences between the two scenarios for some of the foods and food components considered, when normality of the transformed intake data was not an appropriate assumption.

For some individuals, we estimated small negative intakes in the alternative scenario for red and processed meat. These individuals constituted a very small proportion of the total population $(<1 \%)$, and thus, the negative intakes were rounded to zero. This incoherency can be explained by the differences in the within- and between-individual variances in the reference and alternative scenario, induced by the substitution model. These differences caused different levels of shrinkage of the intake in the reference scenario compared to the shrinkage of the intake difference. Specifically, for fish intakes we found that the within-individual variability was reduced to zero after substitution on individual days with a non-zero fish intake before substitution and increased 
intake after (i.e. days that were subject to proportional increases in intake amounts). On the other hand, on new individual fish intake days, the between-individual variance was zero after substitution. These observations give insight in the behavior of the substitution model. Indeed, individual fish consumption days before substitution became more alike after substitution due to the proportional increase in intake amounts when the increase in fish consumption frequency was not sufficient to reach the weekly target fish consumption. When the within-individual variance was zero, there was no need to apply the four-part UID model and we simply applied the OIM for those substitution days. Meanwhile, individuals became more alike on days with zero fish consumption before substitution but with non-zero consumption after, because intake amounts were sampled from the same distribution across the population.

The health impact of substituting red and processed meat with fish varied considerably between subgroups in the Danish population, with some subgroups experiencing a health gain and other subgroups experiencing no health gain or even a health loss. Furthermore, the health impact of the substitution varied within subgroups. A large part of the health gain that we estimated for the substitution was experienced by women in the childbearing age. The estimated health impact for these women partly resulted from the age-dependent probability of giving birth to a child that may experience a beneficial or adverse effect due to nutrients and contaminants present in fish (cf. Supplemental Material 10). For most women, there was an overall beneficial effect of the increased fish consumption on fetal neurodevelopment, but our results also showed that the substitution caused some women to increase their intakes of MeHg to levels where beneficial nutrients in fish cannot compensate for the adverse effects of MeHg. Previous studies have investigated the riskbenefit balance of various fish species and found that consumption of large predatory fish species should be limited among children and women in the childbearing age (Groth 2017; Jacobs et al. 
2017; Zeilmaker et al. 2013). In a Danish context, this mainly concerns consumption of tuna (Thomsen et al. 2018).

The effects of fish consumption on fetal neurodevelopment, including that attributed maternal $\mathrm{MeHg}$ exposure, were assigned to these women but the effect will be experienced by their children. Likewise, the increased burden of male infertility due to increased maternal exposure to dioxin and dl-PCBs will be borne by unborn children. The health loss associated with increased male infertility was negligibly small compared to the effects on fetal neurodevelopment and did not have any considerable effect on the overall risk-benefit balance of the substitution. Nonetheless, while increased intelligence may dominate over decreased male fertility in terms of DALYs on a population level, this is not necessarily true at the individual level. The individual that benefits from increased intellectual abilities due to maternal fish consumption during pregnancy may be different from the individual that becomes infertile due to maternal exposure to dioxin and dl-PCBs during pregnancy. Although we estimated less than one case of male infertility per 100,000 due to increased exposure to dioxin and dl-PCBs in women in the childbearing age, this is important to bear in mind. Another large part of the overall health gain of the substitution was assigned to individuals around or above 50 years of age and in particular men. The majority of the health gain was attributed to an increased intake of DHA and EPA causing a decreased risk of fatal CHD, whereas a decreased intake of red and processed meat caused a smaller, but not negligible health gain due to a decrease in cancer risk, in particular CRC. Due to data gaps and constraints in the disease models, we assumed that there would not be a time lag from change in food consumption to an effect for any of the health outcomes. This seems to be a reasonable assumption for the effects of DHA and EPA on fatal CHD risk, as these fatty acids have been found to induce a beneficial effect on fatal CHD risk within a short time frame (Mozaffarian and Rimm 2006). However, the assumption appears to be less reasonable for e.g. cancer risk. The beneficial health impact of 
decreased consumption of red and processed meat in primarily the older generation was more a result of a higher cancer incidence in this subgroup compared to the young generation than of the changes in consumption habits for this specific subgroup. Since the incidence of cancer in the young generation is very low, we did not estimate a considerable health impact for this subgroup. Our approach of basing the DALY calculations on the current incidence of diseases (for fatal CHD, CRC, and NCSC) is also referred to as the directly attributable annual health loss method and the limitations of this method have been discussed by others (Hoekstra et al. 2012; van Kreijl et al. 2006). In addition to the lack of accounting for delay in disease, which makes interpretation of the results difficult, the limitation of not accounting for co-morbidity in the model was also highlighted as a limitation of this approach. A solution to these limitations have been proposed by another but more complex disease model (Hoogenveen et al. 1998; van Kreijl et al. 2006).

We also assessed the change in intake of vitamin $\mathrm{D}$, iron, and energy, due to the substitution. We found that the substitution decreased the fraction of the population at risk of inadequate vitamin $\mathrm{D}$ intake by $25 \%$ while no marked changes were observed in iron intake. This is in line with previous findings (Tetens et al. 2013b). The distribution of requirement for iron is known to be highly skewed for women in the childbearing age and our estimates may therefore underestimate the true proportion of women with inadequate intakes (EFSA 2015; The Scientific Advisory Committee on Nutrition 2010). Thus, our estimates should mainly be considered with regard to the (lack of) change in the proportion of women with inadequate intakes rather than the absolute proportion in each scenario.

The substitution had a large influence on the energy intake in the population, with individual estimates ranging from decreases to increases in individual energy intake across the population. The average change was almost $800 \mathrm{~kJ}$ increase in energy intake per week. Even small increases in energy intake may lead to overweight and associated diseases on the long-term causing the risk- 
benefit balance to be affected. However, we were not able to quantify these potential consequences in terms of DALYs. In the current study, we only considered a small fraction of the whole diet. Had the whole diet been taken into account in our calculations, the increase in energy intake may have been compensated by a decrease in consumption of other foods than those included in this study (Willett et al. 1997).

The need for including variability in RBA has been previously stressed (Hart et al. 2013; Nauta et al. 2018). Variability was also taken into account in another RBA of increased fish consumption (Hoekstra et al. 2013). This study also showed the benefit of increased fish consumption increases with age due to the simultaneous increase in the background incidence of fatal CHD. A less pronounced health gain was observed for women in the childbearing age. Indeed, more women were estimated to experience a health loss due to adverse effects of MeHg and dioxins in unborn children. The differences between the approach taken for characterizing health effects in the RBA by Hoekstra $e t$ al. and our study, explaining some of the differences in individual health impact, are discussed in Thomsen et al. (Thomsen et al. 2018).

Other studies have investigated the impact of substituting between different food groups on nutrient intakes (Hollander et al. 2018; Roodenburg et al. 2013; Temme et al. 2015, 2011, 2013; Tetens et al. 2013b; van der Voet et al. 2007). Van der Voet et al. substituted meat on fractions of meat consumption days by fish while others substituted fractions of meat consumption amounts by plantbased foods (Temme et al. 2015, 2013). In another study, the substitution of foods not complying with Dutch health logo criteria were substituted with foods that did comply with these criteria (Roodenburg et al. 2013; Temme et al. 2011). Hollander et al. substituted meat by fish in order to reach the adequate intake of $250 \mathrm{~g} /$ day of DHA and EPA. All these studies performed the substitution on an individual level and applying a gram by gram substitution in terms of food amounts (by weight). All studies investigated the impact of the substitution on nutrient intakes and 
one study additionally considered contaminant intakes. The health impact in terms of a common health metric of these changes was only quantified in one study (Hollander et al. 2018).

Our results of the health impact of the substitution are, on the population level, overall comparable with the health impact estimated for substituting red and processed meat by a mix of fish species (alternative scenario 1) in the RBA by Thomsen et al. (Thomsen et al. 2018). We estimated a slightly lower benefit of the substitution, although the average fish consumption in our study was higher, and the meat consumption lower, after substitution in the current study. Taking an individual-based approach, non-linearities in the model used in the current study could potentially cause differences in the results at the population level when compared with the population-based approach by Thomsen et al. However, this does not seem to be the case. The probabilistic approach taken in the present study adds to the previous study by allowing us to i) adjust the individual intakes and intake differences for within-individual variability, while keeping information on each individual, ii) mimic the variability in substitution behaviors upon implementation of a public health strategy, and iii) assess the variability in the associated individual health impact. Our study provides increased insight in the variability in health impact upon implementation of a public health strategy and emphasizes the need for public guidance targeted towards specific groups in the population.

Our model improves previous methods that estimated health gains and losses at the population level. By calculating DALYs on an individual level, we were able to take into account potential correlation between individual changes in consumption of different foods and the final health impact. This was particularly relevant for coupling correlated intakes such as individual fish consumption and $\mathrm{MeHg}$ exposure to assess the combined impact on fetal neurodevelopment. We performed the DALY calculations on an individual level to be able to investigate the variability in the health impact of the substitution. For illustration, these DALY differences were translated into 
differences in healthy life-days lost. The individual estimates of differences in health loss should be interpreted as average potential health impact for subgroups of same age, sex and consumption habits (Hoekstra et al. 2012). While some individuals in a given subgroup may fall ill and experience a loss of healthy life years due to their diet, others will not. However, the burden experienced by those falling ill, is averaged over a large group of similar individuals. The individual DALYs estimated in our study should not be confused with estimates of DALYs per case, which is an estimate of the loss of healthy life years of those falling ill (Devleesschauwer et al. 2014).

Many of the same unquantified uncertainties listed by Thomsen et al. apply to the current study (Thomsen et al. 2018). These include uncertainties in the data applied, such as consumption data, concentration data, and the data and models used for estimating DALYs. Additionally in this study, uncertainty is associated with the fitted models used to describe individual usual intakes.

Furthermore, the modeled substitution behavior is also associated with a likely high uncertainty; however, this was not quantified in the present study.

After the termination of our study, the European Food Safety Authority (EFSA) set a new TWI for dioxin and dl-PCBs at $2 \mathrm{pg}$ TEQ/kg bw/week based on the availability of new epidemiological data on the developmental reproductive effects of dioxin and dl-PCBs and on the development of new modeling techniques (EFSA CONTAM Panel 2018). We have not modified our results to include these new data or the new TWI, as the current study serves to compare with the previous RBA by Thomsen et al. (Thomsen et al. 2018). Considering the new evidence would imply a substantial increase in the proportion of the population with exposures exceeding the TWI, both before and after substitution, and potentially an increase in the extra number of cases of male infertility among unborn children. Public health strategies, including dietary recommendations, should take this into account. 
We took an individually-based approach in modeling food substitution, describing the usual intake difference between two scenarios and quantifying the associated health impact. The same approach may be applied to other RBAs investigating the health impact of food substitution to provide answers on the health impact on public health interventions. The substitution model may also be extended to include other foods, and thus get one step closer to assessing the health impact of the whole diet of individuals.

\section{Conclusions}

We applied probabilistic methods to model and assess the variability in food substitution behavior and the associated health impact in the Danish adult population. We estimated that a total of 5,786 $(4,390 ; 7,299)$ DALYs could be averted per year in Denmark if part of the red and processed meat consumed was substituted by a mix of commonly consumed fish in the Danish adult population (1575 years) in order for $70 \%$ of the population to reach at least the recommended level of $350 \mathrm{~g}$ of fish/week. The health impact of the substitution varied considerably with varying age and sex, with the largest health benefit being assigned to young women and the older generation, mainly men. Furthermore, our results showed that not all individuals will experience a health gain and some, mainly among women in the childbearing, were assigned an overall health loss. Finally we propose a method for adjustment of intake differences for individual day-to-day variability, when assessing consumption changes in RBA to allow for an assessment of between-individual variability without the within-individual variability in intakes. Our study provides further insight in how the health impact of substituting meat by fish varies between individuals and suggests a framework that can be applied in RBAs of other food substitutions as well. The results are relevant for public health and food safety policy making in helping define more targeted evidence-based public health strategies. 


\section{Acknowledgements}

We thank Tue Christensen for retrieving the consumption data from DANSDA 2011-2013. This work was funded through the Metrix project by the Danish Ministry for Environment and Food. 


\section{References}

Black AE. 2000. The sensitivity and specificity of the Goldberg cut-off for EI:BMR for identifying diet reports of poor validity. Eur. J. Clin. Nutr. 54:395-404; doi:10.1038/sj.ejcn.1600971.

de Boer WJ, van der Voet H, Bokkers BGH, Bakker MI, Boon PE. 2009. Comparison of two models for the estimation of usual intake addressing zero consumption and non-normality. Food Addit. Contam. - Part A Chem. Anal. Control. Expo. Risk Assess. 26:1433-1449; doi:10.1080/02652030903161606.

Devleesschauwer B, Haagsma JA, Angulo FJ, Bellinger DC, Cole D, Döpfer D, et al. 2015. Methodological framework for World Health Organization estimates of the global burden of foodborne disease. PLoS One 10:1-20; doi:10.1371/journal.pone.0142498.

Devleesschauwer B, Havelaar AH, Maertens De Noordhout C, Haagsma JA, Praet N, Dorny P, et al. 2014. Calculating disability-adjusted life years to quantify burden of disease. Int. J. Public Health 59:565-569; doi:10.1007/s00038-014-0552-z.

DTU. 2017. Fooddata R2, National Food Institute, Technical University of Denmark. Available: http://frida.fooddata.dk/ [accessed 25 January 2017].

EFSA. 2012. Guidance on the Use of Probabilistic Methodology for Modelling Dietary Exposure to Pesticide Residues. EFSA J. 10:2839; doi:10.2903/j.efsa.2012.2839.

EFSA. 2015. Scientific Opinion on Dietary Reference Values for iron. EFSA J. 13:4254; doi:10.2903/j.efsa.2015.4254.

EFSA CONTAM Panel. 2012. EFSA Panel on Contaminants in the Food Chain (CONTAM); 
Scientific Opinion on the risk for public health related to the presence of mercury and methylmercury in food. EFSA J. 10(12):2985 [241 pp]; doi:10.2903/j.efsa.2012.2985.

EFSA CONTAM Panel. 2018. Risk for animal and human health related to the presence of dioxins and dioxin - like PCBs in feed and food. EFSA J. 16(11):5333; doi:10.2903/j.efsa.2018.5333.

EFSA NDA Panel. 2010a. EFSA Panel on Dietetic Products, Nutrition, and Allergies (NDA); Scientific Opinion on Dietary Reference Values for fats, including saturated fatty acids, polyunsaturated fatty acids, monounsaturated fatty acids, trans fatty acids, and cholesterol. EFSA J. 2010;8(3):1461 [107 pp.]; doi:10.2903/j.efsa.2010.1461.

EFSA NDA Panel. 2010b. Guidance on human health risk-benefit assessment of food. EFSA J. 8:1-40; doi:10.2093/j.efsa.2010.1673.

FAO. 2010. Fats and fatty acids in human nutrition - Report of an expert consultation. Geneva 2008. FAO Food and Nutrition Paper 91, 2010. 1-166; doi:978-92-5-106733-8. Available: http://www.ncbi.nlm.nih.gov/pubmed/21812367 [accessed 18 January 2018].

Fransen H, De Jong N, Hendriksen M, Mengelers M, Castenmiller J, Hoekstra J, et al. 2010. A tiered approach for risk-benefit assessment of foods. Risk Anal. 30:808-816; doi:10.1111/j.1539-6924.2009.01350.x.

GBD 2017 Risk Factor Collaborators. 2018. Global, regional, and national comparative risk assessment of 84 behavioural, environmental and occupational, and metabolic risks or clusters of risks for 195 countries and territories, 1990-2017: a systematic analysis for the GBD Study. Lancet 392:1923-94; doi:10.1016/S0140-6736(18)31891-9.

Goedhart PW, Voet H, Knüppel S, Dekkers ALM, Dodd KW, Boeing H, et al. 2012. A comparison by simulation of different methods to estimate the usual intake distribution for episodically 
consumed foods. EFSA Support. Publ. 9; doi:10.2903/SP.EFSA.2012.EN-299.

Groth E. 2017. Scientific foundations of fish-consumption advice for pregnant women:

Epidemiological evidence, benefit-risk modeling, and an integrated approach. Environ. Res. 152:386-406; doi:10.1016/j.envres.2016.07.022.

Hart A, Hoekstra J, Owen H, Kennedy M, Zeilmaker MJ, de Jong N, et al. 2013. Qalibra: A general model for food risk-benefit assessment that quantifies variability and uncertainty. Food Chem. Toxicol. 54:4-17; doi:10.1016/j.fct.2012.11.056.

Hendriksen MA, Tijhuis MJ, Fransen HP, Verhagen H, Hoekstra J. 2011. Impact of substituting added sugar in carbonated soft drinks by intense sweeteners in young adults in the Netherlands: example of a benefit-risk approach. Eur. J. Nutr. 50:41-51; doi:10.1007/s00394010-0113-z.

Henry C. 2005. Basal metabolic rate studies in humans: measurement and development of new equations. Public Health Nutr. 8:1133-1152; doi:10.1079/PHN2005801.

Hoekstra J, Hart A, Boobis A, Claupein E, Cockburn A, Hunt A, et al. 2012. BRAFO tiered approach for benefit-risk assessment of foods. Food Chem. Toxicol. 50:S684-S698; doi:10.1016/j.fct.2010.05.049.

Hoekstra J, Hart A, Owen H, Zeilmaker M, Bokkers B, Thorgilsson B, et al. 2013. Fish, contaminants and human health: Quantifying and weighing benefits and risks. Food Chem. Toxicol. 54:18-29; doi:10.1016/j.fct.2012.01.013.

Hollander A, De Jonge R, Biesbroek S, Hoekstra J, Zijp MC. 2018. Exploring solutions for healthy, safe, and sustainable fatty acids (EPA and DHA) consumption in The Netherlands. Sustain. Sci.; doi:https://doi.org/10.1007/s11625-018-0607-9. 
Hoogenveen RT, Hoogenveen AEM, Genugten M van LL van. 1998. The chronic diseases modelling approach. Report no. 266750001.

Husøy T, Mangschou B, Fotland TØ, Kolset SO, Nøtvik Jakobsen H, Tømmerberg I, et al. 2008. Reducing added sugar intake in Norway by replacing sugar sweetened beverages with beverages containing intense sweeteners - a risk benefit assessment. Food Chem. Toxicol. 46:3099-105; doi:10.1016/j.fct.2008.06.013.

Jacobs S, Sioen I, Jacxsens L, Domingo JL, Sloth JJ, Marques A, et al. 2017. Risk assessment of methylmercury in five European countries considering the national seafood consumption patterns. Food Chem. Toxicol. 104:26-34; doi:10.1016/j.fct.2016.10.026.

Koch AL. 1966. The logarithm in biology 1. Mechanisms generating the log-normal distribution exactly. J. Theor. Biol. 12:276-290; doi:10.1016/0022-5193(66)90119-6.

Larsen EH, Andersen NL, Moller A, Petersen A, Mortensen GK, Petersen J. 2002. Monitoring the content and intake of trace elements from food in Denmark. Food Addit. Contam. 19:33-46; doi:10.1080/02652030110087447.

Lesaffre E, Lawson AB. 2012. Bayesian Biostatistics. John Wiley \& Sons, Ltd.

Mozaffarian D, Rimm EB. 2006. Fish Intake, Contaminants, and Human Health: Evaluating the Risks and the Benefits. Jama 296:1885-1900; doi:10.1001/jama.296.15.1885.

Nauta MJ, Andersen R, Pilegaard K, Pires SM, Ravn-Haren G, Tetens I, et al. 2018. Meeting the challenges in the development of risk-benefit assessment of foods. Trends Food Sci. Technol. 76:90-100; doi:10.1016/j.tifs.2018.04.004.

Nordic Council of Ministers. 2006. A better life through diet and physical activity Nordic Plan of 
Action on better health and quality of life through diet and physical activity. Available: http://norden.diva-portal.org/smash/get/diva2:701045/FULLTEXT01.pdf [accessed 22 June 2018].

Nordic Council of Ministers. 2014. Nordic Nutrition Recommendations 2012 - Integrating nutrition and physical activity. 5th ed. Norden:Copenhagen, Denmark.

Pedersen AN, Christensen T, Knudsen J, Matthiessen VK, Rosenlund-Sørensen M, Biltoft-Jensen A, et al. 2015. Danskernes kostvaner 2011-2013. Hovedresultater [Dietary habits in Denmark 2011-2013. Main results]. National Food Institute, Technical University of Denmark. Søborg, Denmark. 1-209. Available: http://www.food.dtu.dk//media/Institutter/Foedevareinstituttet/Publikationer/Pub-2015/Rapport_DanskernesKostvaner-2011-2013.ashx?la=da [accessed 1 June 2016].

Petersen A, Fromberg A, Andersen JH, Sloth JJ, Granby K, Duedahl-Olesen L, et al. 2015a. Chemical contaminants - Food Monitoring 2004-2011. 3rd edition. National Food Institute, Technical University of Denmark.

Petersen A, Fromberg A, Andersen JH, Sloth JJ, Granby K, Duedahl-Olesen L, et al. 2015b. Chemical Contaminants - Food Monitoring 2012-2013. 1st edition. National Food Institute, Technical University of Denmark.; doi:10.1016/B978-0-12-064477-3.50018-7.

R Core Team. 2018. R: A language and environment for statistical computing. R Foundation for Statistical Computing, Vienna, Austria. Available: https://www.r-project.org/.

Roodenburg AJC, van Ballegooijen AJ, Dötsch-Klerk M, van der Voet H, Seidell JC. 2013. Modelling of Usual Nutrient Intakes: Potential Impact of the Choices Programme on Nutrient Intakes in Young Dutch Adults. PLoS One 8; doi:10.1371/journal.pone.0072378. 
Sakia BRM. 1990. Retransformation Bias: A Look at the Box-Cox Transformation to Linear Balanced Mixed ANOVA Models. Metrika 37: 345-351.

Scientific Committee on Food. 2001. Opinion of the Scientific Committee on Food on the Risk Assessment of Dioxins and Dioxin-like PCBs in Food. Update based on new scientific information available since the adoption of the SFC opinion of 22nd november 2000. Adopted on 30 May 2001. European. 1-29. Available:

https://ec.europa.eu/food/sites/food/files/safety/docs/cs_contaminants_catalogue_dioxins_out9 0_en.pdf [accessed 3 June 2016].

Slob W. 2006. Probabilistic dietary exposure assessment taking into account variability in both amount and frequency of consumption. Food Chem. Toxicol. 44:933-951; doi:10.1016/j.fct.2005.11.001.

Temme EHM, Bakker HME, Seves SM, Verkaik-Kloosterman J, Dekkers AL, Van Raaij JMA, et al. 2015. How may a shift towards a more sustainable food consumption pattern affect nutrient intakes of Dutch children? Public Health Nutr. 18:2468-2478;

doi:10.1017/S1368980015002426.

Temme EHM, Van Der Voet H, Roodenburg AJC, Bulder A, Van Donkersgoed G, Van Klaveren J. 2011. Impact of foods with health logo on saturated fat, sodium and sugar intake of young Dutch adults. Public Health Nutr. 14:635-644; doi:10.1017/S1368980010002089.

Temme EHM, Van Der Voet H, Thissen JTNM, Verkaik-Kloosterman J, Van Donkersgoed G, Nonhebel S. 2013. Replacement of meat and dairy by plant-derived foods: Estimated effects on land use, iron and SFA intakes in young Dutch adult females. Public Health Nutr. 16:19001907; doi:10.1017/S1368980013000232. 
Tetens I, Andersen LB, Astrup A, Mejborn UH, Gondolf Kjeld H, Marianne UJ, et al. 2013a. Evidensgrundlaget for danske råd om kost og fysisk aktivitet [The evidence-base for the Danish guidelines for diet and physical activity]. National Food Institute, Technical University of Denmark. Søborg, Denmark.

Tetens I, Hoppe C, Andersen LF, Helldán A, Lemming EW, Trolle E, et al. 2013b. Nutritional evaluation of lowering consumption of meat and meat products in the Nordic context. Norden:Copenhagen, Denmark.

The Scientific Advisory Committee on Nutrition. 2010. Iron and Health. TSO:London, UK.

Thomsen ST, Pires SM, Devleesschauwer B, Poulsen M, Fagt S, Ygil KH, et al. 2018. Investigating the risk-benefit balance of substituting red and processed meat with fish in a Danish diet. Food Chem. Toxicol. 120:50-63; doi:10.1016/j.fct.2018.06.063.

Tijhuis MJ, De Jong N, Pohjola M V, Gunnlaugsdóttir H, Hendriksen M, Hoekstra J, et al. 2012. State of the art in benefit risk analysis: Food and nutrition. Food Chem. Toxicol. 50:5-25; doi:10.1016/j.fct.2011.06.010.

van der Voet H, de Boer WJ, Kruisselbrink JW, Goedhart PW, van der Heijden GWAM, Kennedy MC, et al. 2015. The MCRA model for probabilistic single-compound and cumulative risk assessment of pesticides. Food Chem. Toxicol. 79:5-12; doi:10.1016/j.fct.2014.10.014.

van der Voet H, de Mul A, van Klaveren J. 2007. A probabilistic model for simultaneous exposure to multiple compounds from food and its use for risk-benefit assessment. Food Chem. Toxicol. 45:1496-1506; doi:10.1016/j.fct.2007.02.009.

van Kreijl CF, Knaap a. G a. C, Raaij JM a. Van. 2006. Our food, our health. Healthy diet and safe food in the Netherlands. RIVM, Bilthoven, The Netherlands. 
Verhagen H, Andersen R, Antoine JM, Finglas P, Hoekstra J, Kardinaal A, et al. 2012. Application of the BRAFO tiered approach for benefit-risk assessment to case studies on dietary interventions. Food Chem. Toxicol. 50:S710-S723; doi:10.1016/j.fct.2011.06.068.

WHO. 2000. Executive summary of the Assessment of the health risk of dioxins: Re-evaluation of the tolerable daily intake (TDI). WHO Consultation, May 1998, Geneva.; doi:10.1080/713810655. Available: http://www.who.int/ipcs/publications/en/exe-sum-final.pdf [accessed 15 December 2016].

WHO. 2017. WHO methods and data sources for global burden of disease estimates 2000-2015. Global Health Estimates Technical Paper WHO/HIS/IER/GHE/2017.1. World Health Organization, Geneva, Switzerland.

Willett WC, Howe GR, Kushi L. 1997. Adjustmentfor total energy intake in epidemiologic studies. Am. J. Clin. Nutr. 65:1220S-1228S; doi:10.1007/s13398-014-0173-7.2.

Zeilmaker MJ, Hoekstra J, van Eijkeren JCH, de Jong N, Hart A, Kennedy M, et al. 2013. Fish consumption during child bearing age: A quantitative risk-benefit analysis on neurodevelopment. Food Chem. Toxicol. 54:30-34; doi:10.1016/j.fct.2011.10.068. 


\section{Highlights:}

- The variability in the health impact of substituting red and processed meat by fish in Danish adults was investigated.

- A probabilistic substitution model was applied to reflect variability between individual substitution behaviors.

- A method for adjustment of intake differences for within-individual variability was proposed.

- The health impact varied by age and sex, with young women and elderly, mainly men, experiencing the largest health gain.

- The results provide support for more targeted public health strategies. 